\title{
RELIABILITY OF THE USE OF CODES OF PRACTICES DEFLECTION EQUATIONS TO COMPUTE THE SHORT TIME DEFLECTION
}

\author{
L. M. ABDEL-HAFEZ \\ Associate Professor, Civil Engineering Department, Minia University, \\ Minia, Egypt
}

(Received December 1, 2005 Accepted December 18, 2005)

\begin{abstract}
There is remarkably little agreement in the literature, regarding the codes of practice formulae of predicting deflections in reinforced concrete beams. Therefore, it was decided to carry-out tests on beams made of higher-strength steels and concretes. In this paper, typical experimental results are presented and discussed. Comparisons of the results with values predicted analytically by using various codes of practices are given.
\end{abstract}

\section{1- INTORDUCTION}

The use and reliance on the probability based limit states design methods has focused attention on the problems of serviceability. These methods, along with development of higher-strength steels and concretes and the use of lighter and less rigid building materials, have led to more flexible and lightly damped structures than ever before, making serviceability problems more prevalent. Most of the current codes of practice include limits on permissible deflection of the reinforced concrete members and formulae for predication of design deflection. However as there is remarkable little agreement, internationally, on the computed values of deflections based on these formulae $[1-4]$, it was decided to carryout tests in flexural beams made of higherstrength steels and concretes.

The principal aspects of material behavior related to the deformation of concrete structures are normally referred to as semi plastic, cracking, creep, shrinkage, and temperature and relaxation effects. The general quality of concrete and the influence of time dependent hydration process are important functions of concrete deformation. Additional factors such as environmental conditions, member size and shape, stress history, concrete mix, etc., affect the deformational behavior of concrete as well. It is important to consider the effect of both applied forces and applied deformation (e. g. shrinkage and temperature movements on the serviceability limit state). This paper is limited to deflections due to applied load only. The purpose of this paper is to evaluate the reliability of the use of codes of practices [5 - 8] deflection equations to calculate the Short Time Deflection of under reinforced concrete beams failed in bending at service limit due to applied load only. Taking into account some principal factors, which may affect the initial deflection under service 
loads such as concrete grade, beam span to depth ratio, section reinforcement (percentage of main steel reinforcement, compression steel, shrinkage steel and stirrups) and the existence of the flange in tension zone.

\section{2- IMMEDIATE DEFLECTION IN THE MEMBER SUBJECTED TO BENDING MOMENT M, SHEAR FORECE Q AND AXIAL FORCE F}

The Bending Moment M: The bending moment $\mathrm{M}$ causes a change in curvature. If the simplifying assumption that plane section remains plane before and after bending is made and the terms of second order are ignored then the moment-curvature relationship is given by

$$
\mathrm{M}=\mathrm{EI} \frac{\partial^{2} w}{\partial^{2} x}
$$

Where EI= flexural rigidity, $\mathrm{W}$ lateral deflection

Integration of the moment-curvature relationship satisfying the prescribed boundary condition gives the value of $\mathrm{w}$. This deflection resulting solely from curvature changes is called the bending deflection.

Shear force $Q$ : the shear force $\mathrm{Q}$ causes shear stress $\tau$ that is non-uniformly distributed over the cross section. The stress $\tau$ has a maximum value at the neutral axis. Since the stress $\tau$ is not constant over the cross section, the distortion (shear strain) of the cross section is also not constant and an average value for the whole section is given by

$$
\frac{\partial w}{\partial x} \approx \frac{\tau}{G}=\gamma \frac{Q}{A G}
$$

Where $\mathrm{A}$, is area of cross section, $\mathrm{G}$ is the shear modulus, $\gamma$ a factor to reflect the effect of non-uniform distribution of shear stress on the average distortion.

The displacement $\mathrm{w}$, resulting from the distortion caused by shear force is called the deformation due to shear.

Axial force $\mathrm{F}$ : The axial force $\mathrm{F}$ causes an axial normal stress $\sigma_{a}$ and a net axial displacement $u_{p}$. In addition to these effects, the axial force causes a bending moment due to the eccentricity of the axial load with respect to the deformed position of structure. This effect makes the load deformation behavior of structure non-linear.

The total displacement is sum of displacements due to change in curvature caused by bending $\mathrm{M}$ and the displacement resulting from the distortion caused by shear force $\mathrm{Q}$. Generally the bending deformation is the major component of the total displacement except in the case of beams with low span to depth ratio.

Deflection Due to shrinkage: concrete shrinkage in both statically determinate and indeterminate reinforced concrete structures induces compressive stresses in the steel, which are equilibrated by tensile stresses in concrete. When the reinforcement is unsymmetrical, the resulting nonuniform strain distribution and accompanying warping cause deflections as those caused by loads for which the structure was designed reinforced. 


\section{3- METHODS OF COMPUTING INITIAL DEFLECTION}

\section{3-1 Based On The Linear Elastic Analysis}

(a) Due to Bending Deformation: Different methods of computing initial deflections can be found in textbooks $[9,10]$. These methods based on elastic theory equations. In its simple form the equation for computing deflection can be expressed as

$$
\delta=\frac{k M_{a} L^{2}}{E_{c} I_{e}}
$$

Where $\mathrm{K}$ is a deflection coefficient that depends on the load distribution and supports conditions, $\mathrm{M}_{\mathrm{a}}$ is the maximum moment and $\mathrm{I}_{\mathrm{e}}$ is the average moment of inertia. The principal factors which affect the initial or short-time deflection of reinforced concrete flexural members under service load based on the elastic theory are modulus of elasticity $E_{c}$, loads distribution and support conditions, variable cross-section, load level and degree of cracking along the beam.

The modulus of elasticity of concrete: a major difficulty in the application of elastic theory to reinforced concrete members is the inelasticity of concrete. The modulus of elasticity of concrete is dependent on both the level stress and time of loading. The value of modulus of elasticity $E_{c}$ for concrete given by empirical equations based on concrete weight or concrete compressive strength is stating in references [5, 6 and 8$]$

The moment of inertia I: depends on the amount of cracking has taken placed in the member. The decrease in moment of inertia caused by cracking of concrete has appreciable effect on deflection and the uncertainty of the extent of cracking makes the effective moment of inertia of members difficult to estimate. The value of moment of inertia in the almost methods of computing deflection based on the cracking transformed section through the span is given in reference [9].

(b) Due to Bending and Shear Deformation: Based on the derivation of element stiffness matrix shear deformation can be including with bending deformation as given in reference [11]. This method has the same difficulty in determination of modulus of elasticity of concrete and the moment of inertia of the cracked section.

\section{3-2 Base On Nonlinear Analysis}

Because of shrinkage and cracks under sustained loading deformations of reinforced concrete members even under working loads strictly requires a non-Linear analysis $[12-16]$.

\section{4- INITIAL DEFLECTION OF FLEXURAL BEAMS IN DIFFERENT CODES}

In codes, where deflections are to be computed, deflections that occur immediately on application of load shall be computed by usual methods or formulas for elastic deflections, considering effects of cracking and reinforcement.

In ACI [6 ] and E.C.O [5] , immediate deflection shall be computed with modulus of $E_{c}$ for concrete as specified in (normal Wight or light-weight concrete) and with the effective moment of inertia as follows, but not greeter than $I_{g}$ 


$$
I_{e}=\left(\frac{M_{c r}}{M_{a}}\right)^{a} I_{g}+\left[1-\left(\frac{M_{c r}}{M_{a}}\right)^{a}\right] I_{c r}
$$

Where $I_{g}=$ moment of inertia of the gross uncracked section, $I_{c r}=$ moment of inertia of cracked section transformed to concrete, $\mathrm{M}_{\mathrm{a}}=$ maximum moment in member at stage at which the deflection is being computed and

$$
\mathrm{M}_{\mathrm{cr}}=\frac{F_{r} I_{g}}{y_{t}}
$$

Where $\mathrm{y}_{\mathrm{t}}=$ distance from centroidal axis of gross section to the extreme tension fiber and $\mathrm{F}_{\mathrm{r}}=$ modulus of rupture $\left(F_{r}=0.6 \sqrt{F_{c u}} \mathrm{KN} / \mathrm{mm}^{2}\right)$, a is a power ranges between (3 - 4) for simply and continuous beams $[5,6]$.

For continuous members, effective moment of inertia shall be permitted to taken as the average of values obtained from equation (4) for the critical positive and negative moments sections.

The method adopted by CP [17] is based on the calculation of curvatures of sections subjected to the appropriate moments, with allowance for creep and shrinkage effects where necessary. There is a tensile resistance of concrete between cracks; the average effect of variation in tensile stress distributions can be considered by assuming triangular distribution of "average" effective stress. The effective stress is specified by $\left(f_{t}=1 \mathrm{~N} / \mathrm{mm}^{2}\right)$ at the centroid of steel. The curvature can be obtained from the relationships

$$
\frac{1}{r_{b}}=\frac{f_{c}}{x E_{c}}=\frac{f_{s}}{(d-x) E_{s}}
$$

Where $\mathrm{x}$ is the neutral axis depth, $f_{c}$ and $f_{s}$ are the stresses in concrete and reinforcement respectively. Assessment of stresses and neutral axis depth can be found by trial and error approach [17]. Deflections are then calculated form these curvatures. The curvature of any section should be taken as the larger value obtained from considering the section.

For the investigated beams in this paper and according to the manner of loading and end condition, the maximum deflection at mid span can be computed according the following elastic equation

$$
\text { Max Deflection }=\frac{P a\left(3 L^{2}-4 a^{2}\right)}{24 E_{c} I_{e}}
$$

Where P, a, L, $E_{c}$ and $I_{e}$ are the applied load, the distance form each support to the two point load, the effective beam span, instantaneous modulus of elasticity and the effective moment of inertia of cross section respectively.

It is worthwhile to mention that The British bridge code BS 5400 [8] states that the stress in steel should not exceed more than 0.8 of its yield strength in steel and the stress in concrete not exceed than 0.5 of the cube strength of concrete at service load under all possible load combinations. 


\section{5- EXPERIMENTAL PROGRAM}

\section{5 -1 Out Line Of The Program}

The experimental program was planned to evaluate the effect of concrete compressive strength, beam span to depth ratio, percentage of compression steel to main steel ratio, percentage of stirrups, shrinkage steel and the presence of flange in tension zone on the value of deflection at service limit and comparing it with that given by the available codes of practice equations. All beams were designed to be under reinforced section to fail in pure bending.

\subsection{Tested Beams}

Seventeen rectangular beams plus two T-beams were tested in this investigation in form of six groups to study the variables mentioned above. In the first group, five rectangular beams were tested. These beams were identical in size, (width, web thickness, overall depth and length) but with different concrete strength (five concrete grades are used C275, C350, C550, C700, and C780 in this group). Beams's dimensions were $12 \mathrm{~cm}$ web width, $20 \mathrm{~cm}$ overall depth and $160 \mathrm{~cm}$ length. All beams were reinforced with $2 \Phi 10 \mathrm{~mm}$ as tension steel and $2 \Phi 8 \mathrm{~mm}$ as compression reinforcement. The stirrups arrangement was $1 \Phi 6 \mathrm{~mm}$ each $15 \mathrm{~cm}$. In the second group, three rectangular beams were also tested. These beams of this group were identical in cross section and steel reinforcement as group one but with different beam length. Three lengths were considered $(100, \mathrm{~cm}, 200 \mathrm{~cm}$, and $300 \mathrm{~cm})$. In the third group, two rectangular beams were also tested. The beams of this group were identical in every thing but different in thickness and overall depth. Two thicknesses were considered $(30 \mathrm{~cm}$, and $40 \mathrm{~cm})$. In the fourth group, two rectangular beams were tested. The beams of this group were identical in width $(12 \mathrm{~cm})$, length $(160 \mathrm{~cm})$ compression steel and percentage of stirrups as same as beams of group one but with different percentages of main reinforcement, percentages of 1.1, and 1.46 were used. In the fifth group, two rectangular beams were tested. The beams of this group were identical to beams of group one but with different percentage of stirrups. Two different arrangements of stirrups were used $(1 \Phi 6 \mathrm{~mm}$ each $12 \mathrm{~cm}$, and $1 \Phi 6 \mathrm{~mm}$ each $10 \mathrm{~cm}$ ). Beam two of group one was used as a basic and control beam in all the above groups. In sixth group, three rectangular beams were tested The beams of this group were identical in width $(12 \mathrm{~cm})$, length $(160 \mathrm{~cm})$ compression steel and percentage of stirrups as same as beams of group but differ in depth to allow for side reinforcement (see table (1). In seventh group, two $\mathrm{T}$ beams were tested. These beams were identical in every thing $(12 \mathrm{~cm}$ web width, $20 \mathrm{~cm}$ overall depth, flange thickness $6.5 \mathrm{~cm}, 160 \mathrm{~cm}$ length and beams were reinforced with $2 \Phi 10 \mathrm{~mm}$ plus one $1 \Phi \mathrm{mm}$ at each corner of the flange as tension steel and $2 \Phi 8 \mathrm{~mm}$ as compression reinforcement. The stirrups arrangement was $1 \Phi 6 \mathrm{~mm}$ each $15 \mathrm{~cm}$ ) but different in flange width. Two widths were used $(30 \mathrm{~cm}$ and 40$)$. All beams of groups two to seven having same concrete mix. The compressive strength was ranged between $340 \mathrm{~kg} / \mathrm{cm}^{2}, 365$ of average value of $350 \mathrm{~kg} / \mathrm{cm}^{2}$. The beams were designed to fail in pure bending. Sufficient percentage of stirrups was used and all longitudinal bars in the test beams were sufficiently well anchored by embodiment to prevent shear failure and premature bond failure. Details of beams are given in table (1) and Fig. (1). 
Table (1): Properties of tested beams.

\begin{tabular}{|c|c|c|c|c|c|c|c|c|c|c|c|c|c|c|}
\hline \multirow{2}{*}{$\begin{array}{l}\dot{0} \\
Z \\
\Xi \\
\tilde{\Xi} \\
\tilde{\Xi}\end{array}$} & \multicolumn{5}{|c|}{ Beam dimension $\mathrm{cm}$} & \multicolumn{4}{|c|}{ Steel Reinforcement mm } & \multirow{2}{*}{ 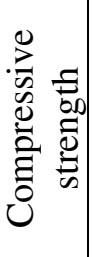 } & \multirow[b]{2}{*}{$\frac{2}{2}$} & \multirow[b]{2}{*}{$\stackrel{\pi}{\Xi}$} & \multirow[b]{2}{*}{$\begin{array}{l}\mu \\
\%\end{array}$} & \multirow[b]{2}{*}{$\mu^{\prime} / \mu$} \\
\hline & $\mathrm{b}$ & $\mathrm{T}$ & 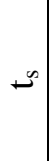 & IاB & $\mathrm{L}_{\mathrm{e}}$ & $\frac{\tilde{\sigma}}{\mathscr{E}}$ & ڤ્छ & 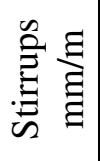 & 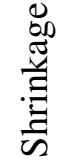 & & & & & \\
\hline \multicolumn{15}{|c|}{ Group one: Effect of compressive strength } \\
\hline 1 & 12 & 20 & - & - & 150 & $2 \Phi 10$ & $2 \varnothing 8$ & $6 \varnothing 6$ & ----- & 27.5 & 8.4 & 3.6 & 0.73 & 0.65 \\
\hline 2 & 12 & 20 & - & & 150 & $2 \Phi 10$ & $2 \varnothing 8$ & $6 \varnothing 6$ & ----- & 35 & \begin{tabular}{|l|}
8.4 \\
\end{tabular} & 3.6 & 0.73 & 0.65 \\
\hline 3 & 12 & 20 & - & - & 150 & $2 \Phi 10$ & $2 \varnothing 8$ & $6 \varnothing 6$ & ----- & 55 & \begin{tabular}{|l|}
8.4 \\
\end{tabular} & 3.6 & 0.73 & 0.65 \\
\hline 4 & 12 & 20 & - & - & 150 & $2 \Phi 10$ & $2 \varnothing 8$ & $6 \varnothing 6$ & $\begin{array}{ll}---- \\
\end{array}$ & 70 & 8.4 & 3.6 & 0.73 & 0.65 \\
\hline 5 & 12 & 20 & - & - & 150 & $2 \Phi 10$ & $2 \varnothing 8$ & $6 \varnothing 6$ & $\begin{array}{ll}---- \\
\end{array}$ & 78 & 8.4 & 3.6 & 0.73 & 0.65 \\
\hline \multicolumn{15}{|c|}{ Group two: Effect of beam length } \\
\hline 6 & 12 & 20 & - & - & 96 & $2 \varnothing 8$ & $2 \varnothing 6$ & $10 \varnothing 6$ & ----- & 35 & 5.3 & 2.1 & 0.46 & 0.56 \\
\hline 2 & 12 & 20 & - & - & 150 & $2 \Phi 10$ & $2 \varnothing 8$ & $6 \varnothing 6$ & --- & 35 & 8.4 & 3.6 & 0.73 & 0.65 \\
\hline 7 & 12 & 20 & - & - & 198 & $2 \Phi 10$ & $2 \varnothing 8$ & $6 \varnothing 6$ & ---- & 35 & 11 & 5 & 0.73 & 0.65 \\
\hline 8 & 12 & 20 & - & - & 292 & $2 \Phi 10$ & $2 \varnothing 8$ & $6 \varnothing 6$ & --- & 35 & 16.3 & 7.5 & 0.73 & 0.65 \\
\hline \multicolumn{15}{|c|}{ Group three: Effect of beam depth } \\
\hline 2 & 12 & 20 & - & - & 150 & $2 \Phi 10$ & $2 \varnothing 8$ & $6 \varnothing 6$ & -- & 35 & 8.4 & 3.6 & 0.73 & 0.65 \\
\hline 9 & 12 & 30 & - & - & 150 & $2 \Phi 10$ & $2 \varnothing 8$ & $6 \varnothing 6$ & -- & 35 & 5.5 & 2.3 & 0.47 & 0.65 \\
\hline 10 & 12 & 40 & - & - & 150 & $2 \Phi 10$ & $2 \varnothing 8$ & $6 \varnothing 6$ & -- & 35 & 4 & 1.7 & 0.34 & 0.65 \\
\hline \multicolumn{15}{|c|}{ Group four: effect of Beam tension reinforcement } \\
\hline 2 & 12 & 20 & - & - & 150 & $2 \Phi 10$ & $2 \varnothing 8$ & $6 \varnothing 6$ & -- & 35 & 8.4 & 3.6 & 0.73 & 0.65 \\
\hline 11 & 12 & 20 & - & - & 150 & $3 \Phi 10$ & $2 \varnothing 8$ & $6 \varnothing 6$ & -- & 35 & 8.4 & 3.6 & 1.1 & 0.42 \\
\hline 12 & 12 & 20 & - & - & 150 & $4 \Phi 10$ & $2 \varnothing 8$ & $6 \varnothing 6$ & -- & 35 & 8.4 & 3.6 & 1.46 & 0.32 \\
\hline \multicolumn{15}{|c|}{ Group five: Effect Beam stirrups } \\
\hline 2 & 12 & 20 & - & - & 150 & $2 \Phi 10$ & $2 \varnothing 8$ & $6 \varnothing 6$ & -- & 35 & 8.4 & 3.6 & 0.73 & 0.65 \\
\hline 13 & 12 & 20 & - & - & 150 & $2 \Phi 10$ & $2 \varnothing 8$ & $8 \emptyset 6$ & -- & 35 & 8.4 & 3.6 & 0.73 & 0.65 \\
\hline 14 & 12 & 20 & - & - & 150 & $3 \Phi 10$ & $2 \varnothing 8$ & $10 \varnothing 6$ & -- & 35 & 8.4 & 3.6 & 0.73 & 0.65 \\
\hline \multicolumn{15}{|c|}{ Group six: effect of beam side reinforcement } \\
\hline 15 & 12 & 30 & & & 150 & $2 \Phi 10$ & $2 \varnothing 8$ & $6 \varnothing 6$ & $2 \Phi 8$ & 35 & 5.5 & 2.3 & 0.47 & 0.65 \\
\hline 16 & 12 & 40 & & & 150 & $4 \Phi 10$ & $2 \varnothing 8$ & $6 \emptyset 6$ & $2 \Phi 8$ & 35 & 4 & 1.76 & 0.71 & 0.32 \\
\hline 17 & 12 & 40 & & & 150 & $4 \Phi 10$ & $2 \varnothing 8$ & $6 \varnothing 6$ & $4 \Phi 8$ & 35 & 4 & 1.76 & 0.71 & 0.32 \\
\hline
\end{tabular}

Group seven: effect of Beam flange (the flange has $6 \varnothing 6 \mathrm{~mm} / \mathrm{m}$ ' stirrups, and its each wing has one bar $6 \mathrm{~mm})$

\begin{tabular}{|l|l|l|l|l|l|l|l|l|l|l|l|l|l|l|}
\hline 18 & 12 & 21 & 6 & 30 & 150 & $2 \Phi 10$ & $2 \varnothing 8$ & $6 \emptyset 6$ & -- & 35 & 8.4 & 3.6 & 0.94 & 0.65 \\
\hline 19 & 12 & 21 & 6 & 40 & 150 & $2 \Phi 10$ & $2 \varnothing 8$ & $6 \varnothing 6$ & -- & 35 & 8.4 & 3.6 & 0.94 & 0.65 \\
\hline
\end{tabular}

Le the effective beam length, $d$ beam depth, a shear span, $t_{s}$ the flange thickness, $B$ the flange width

\section{5-3 Used Material Properties}

The used sand was natural desert sand. It was clean and free from silt and clay. Two types of gravel were used in this work. First one, uncrushed gravel of $25 \mathrm{~mm}$ maximum nominal size was used in mix 1, 2, 3 (see table 2). Second one, first class 
crushed dolomite with a nominal maximum size $1 / 2$ " and $3 / 4$ "were used in mix 4,5. Samples of aggregate were tested to identify their properties. The specific gravity, fines Modulus, and void ratio for sand were 2.56, 2.82, and $36.5 \%$ and for gravel were 2.64, 6.83 , and $33.6 \%$, repetitively Ordinary Portland cement fabricated according to Egyptian Standard specifications No. 372 (1991) was used in all mixes. Also, clean drinking fresh water free from impurities was used for all concrete mixes.

\begin{tabular}{|c|c|c|c|c|c|c|}
\hline $\begin{array}{l}\text { Group } \\
\text { No. }\end{array}$ & $L(m)$ & Le (m) & $H(\mathrm{~cm})$ & $n, D$ & $\begin{array}{l}\text { Stirrups } \\
\mathrm{mm} \backslash \mathrm{m}\end{array}$ & $\begin{array}{l}\text { Side } \\
\text { Steel }\end{array}$ \\
\hline 1 & 1.60 & 1.50 & 20 & $2 \not 10$ & $6 \not 6$ & \\
\hline \multirow{3}{*}{2} & 1 & 0.94 & \multirow{3}{*}{20} & \multirow{3}{*}{$2 \not 10$} & \multirow{3}{*}{$6 \not 66$} & \\
\hline & 2 & 1.92 & & & & \\
\hline & 3 & 2.92 & & & & \\
\hline \multirow{2}{*}{3} & \multirow{2}{*}{1.60} & \multirow{2}{*}{1.50} & 30 & \multirow{2}{*}{$2 \not 10$} & \multirow{2}{*}{$6 \not 06$} & \\
\hline & & & 40 & & & \\
\hline \multirow{2}{*}{4} & \multirow{2}{*}{1.60} & \multirow{2}{*}{1.50} & \multirow{2}{*}{20} & $3 \phi 10$ & \multirow{2}{*}{$6 \not 06$} & \\
\hline & & & & $4 \phi 10$ & & \\
\hline \multirow{2}{*}{5} & \multirow{2}{*}{1.60} & \multirow{2}{*}{1.50} & \multirow[t]{2}{*}{20} & \multirow[b]{2}{*}{$2 \not 10$} & $8 \not 66$ & \\
\hline & & & & & $10 \not 6$ & \\
\hline \multirow{2}{*}{6} & \multirow{2}{*}{1.60} & \multirow{2}{*}{1.50} & 30 & $2 \varnothing 10$ & \multirow{2}{*}{$6 \not \varnothing 6$} & 208 \\
\hline & & & 40 & $\frac{4 \varphi 10}{4 \varnothing 10}$ & & \begin{tabular}{|l|}
448 \\
408 \\
\end{tabular} \\
\hline 7 & 1.60 & 1.50 & 21.50 & $\begin{array}{l}2 \not 10 \\
+2 \not 6\end{array}$ & $6 \not 06$ & \\
\hline
\end{tabular}

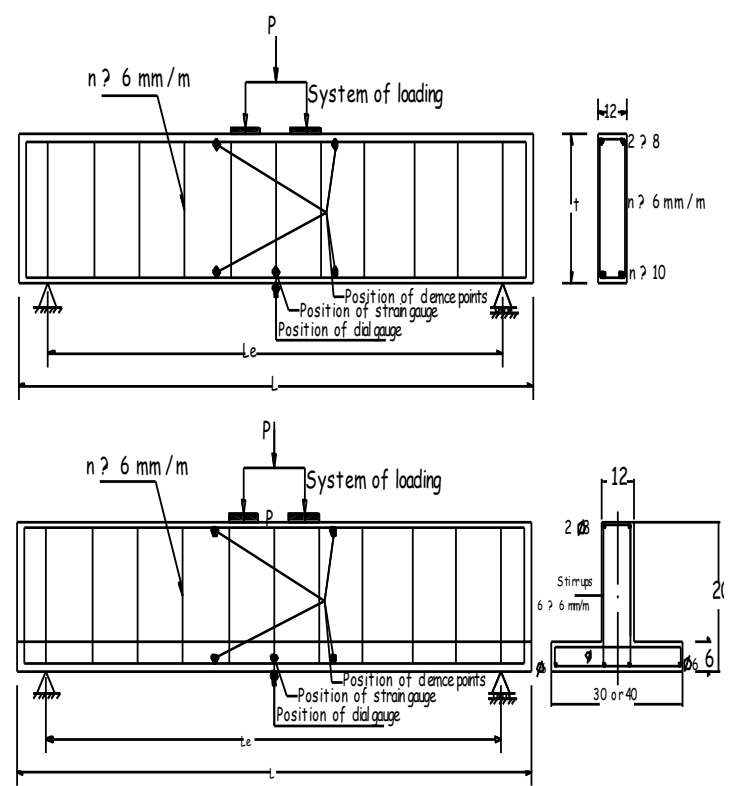

Fig (1) : Geometry, Details of Reinforcement and instrumentations of tested beams

The water cement ratio used was chosen and based on the total weight of water added to the air-dry materials, as no allowance had been made for the absorption of mixing water by the aggregates. Condensed silica fume and high range water reducing (superplasticizer) were used in mixes four and five. Also high range water reducing (superplasticizer) was in mix three. Five concrete mixes design were made to produce concrete having 28-day cubic strength of about $250,350,550,650,800, \mathrm{~kg} / \mathrm{cm}^{2}$. The concrete mixes proportions are detailed in table (2). The used steel in all tested beams was 6,8 , and 10 diameters. Bars of 6 and $8 \mathrm{~mm}$ diameter were of plain normal mild steel but bar of $10 \mathrm{~mm}$ diameter was high grade steel. Mild steel bars of $6 \mathrm{~mm}$ diameter were used for stirrups and the rest of bars used as tension and compression steel. Tension tests were preformed on steel bars samples,. Table (3) gives the mechanical properties of the reinforcing used steel types. For each concrete batch, compressive strength, flexural strength, and modulus of elasticity tests were performed on $15 \times 15 \times 15$ $\mathrm{cm}$ cubes and prism of $10 \times 10 \times 50 \mathrm{~cm}$. Table (4) gives the compressive, flexural strength and modulus of elasticity of the used concrete for each tested beam. 
Table (2): The Proportion of Mixes Constituents by Weight.

\begin{tabular}{|c|c|c|c|c|c|c|c|c|c|}
\hline \multirow[b]{2}{*}{$\begin{array}{l}\sum_{z} \\
\dot{x} \\
\dot{\Sigma}\end{array}$} & \multicolumn{3}{|c|}{$\mathrm{kg} / \mathrm{m}^{3}$} & \multicolumn{3}{|c|}{$\begin{array}{c}\text { Coarse aggregate size one } \\
\mathrm{Kg} / \mathrm{m}^{3}\end{array}$} & \multirow{2}{*}{ 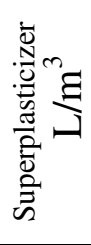 } & \multirow[b]{2}{*}{ 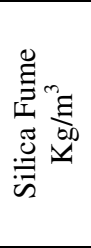 } & \multirow[b]{2}{*}{$\begin{array}{l}\text { The number } \\
\text { of casted } \\
\text { beams using } \\
\text { the mix }\end{array}$} \\
\hline & 苞 & $\begin{array}{l}\frac{\bar{\Xi}}{\pi} \\
\overline{3}\end{array}$ & 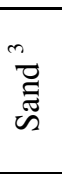 & $\begin{array}{l}\overline{0} \\
\stackrel{0}{0}\end{array}$ & $\begin{array}{l}\text { Crushed } \\
\text { dolomite } \\
\text { M.N.S } 1 / 2 \\
\text { inch }\end{array}$ & $\begin{array}{c}\text { Crushed } \\
\text { dolomite } \\
\text { M.N.S } 3 / 4 \\
\text { inch }\end{array}$ & & & \\
\hline 1 & 350 & 160 & 569 & 1255 & & & & & 1 \\
\hline 2 & 400 & 170 & 580 & 1160 & --- & --- & -- & & Rest of beams \\
\hline 3 & 450 & 162 & 580 & 1160 & - & --- & 18 & & 3 \\
\hline 4 & 450 & 162 & 580 & -- & 580 & 580 & 18 & 45 & 4 \\
\hline 5 & 450 & 162 & 580 & $-\ldots$ & 580 & 580 & 18 & 90 & 5 \\
\hline
\end{tabular}

Table (3): Properties of reinforcing steel bars.

\begin{tabular}{|l|c|c|c|}
\hline Bar diameter $\mathrm{mm}$ & 6 & 8 & 10 \\
\hline Yield stress $\mathrm{KN} / \mathrm{mm}^{2}$ & 240 & 308 & 420 \\
\hline Tensile strength $\mathrm{Kn} / \mathrm{mm}^{2}$ & 300 & 480 & 660 \\
\hline Elongation $\%$ ) & 32 & 31 & 15 \\
\hline Hardening number \% & ---- & ---- & 5 \\
\hline \multicolumn{2}{|r|}{ Note $\Phi 6$ and $8 \mathrm{~mm}$ are mild steel, $\Phi 10$ high tensile steel } \\
\hline
\end{tabular}

Table (4): The average value of compressive modulus of rupture and modulus of elasticity for concrete specimens.

\begin{tabular}{|c|c|c|c|c|c|c|c|c|}
\hline Beam no. & 1 & 2 & 3 & 4 & 5 & $\begin{array}{c}\text { For beam number 6 } \\
\text { to beam } 18\end{array}$ & 19 & 20 \\
\hline $\begin{array}{c}\mathrm{F}_{\mathrm{uc}} \\
\mathrm{KN} / \mathrm{mm}^{2}\end{array}$ & 27.5 & 35 & 55 & 70 & 78 & Average of 35 & 44.5 & 38.5 \\
\hline $\begin{array}{c}\mathrm{F}_{\mathrm{ct}} \\
\mathrm{KN} / \mathrm{mm}^{2}\end{array}$ & 3 & 3.6 & 7.7 & 9.9 & 10.3 & Average of 3.5 & & \\
\hline $\begin{array}{c}\mathrm{E}_{\mathrm{c}} \\
\mathrm{KN} / \mathrm{mm}^{2}\end{array}$ & 21400 & 24300 & 28000 & 33000 & 33000 & Average of 24500 & 2500 & 2700 \\
\hline \multicolumn{7}{|c|}{$\begin{array}{c}\text { Where } \mathrm{F}_{\text {uc }} \text { (cube 28 days strength), } \mathrm{F}_{\mathrm{ct}} \text { (modulus of rupture 28 days), Ec (modulus of } \\
\text { elasticity bending test) }\end{array}$} \\
\hline
\end{tabular}

\section{5-4 Fabrication of Tested Beams}

The fabrication of tested beams started with the formation of steel bars to produce the required arrangement. All beams were casting in a steel mould expect T-beams and the beam with length $3.0 \mathrm{~m}$ were casting in wooden mould. The concrete was mixed mechanically in a horizontal pan type mixer. Dry materials for each mix were prepared by weight according to the proportions mentioned before. The constituents were mixed in dry state for one minute to ensure the uniformity of the mix. Mixing water was then added gradually and the contents were mixed until homogeneous mix was obtained, this took about three minutes. The concrete was placed in the mould by the use of hand shovels. A mechanical vibrator was used in compacting concrete. After twenty-four hours the beam and the cubes were removed from the moulds and they were kept in the 
laboratory temperature, which ranged from $20-30^{\circ} \mathrm{C}$ and sprayed with water every day until the day before testing at age of 28 days. Tests were carried-out on concrete cubes $15.8 \times 15.8 \times 15.8 \mathrm{~cm}$ using the compression testing machine of 100 ton capacity to determine the compressive strength of concrete. The instantaneous modulus of elasticity and flexural strength for the used mixes were determined by testing six standard prisms $(10 \times 10 \times 50 \mathrm{~cm})$ under flexural test. The specimen tested under twopoint load and the corresponding maximum central deflection is recorded at each load increment until failure taking place. The average values for the concrete compressive strength, flexural strength and modulus of elasticity tests were tabulated in Table (4).

\section{5-5 Measurements And Testing Procedure}

The beams with length $160 \mathrm{~cm}$ were tested under monotonically load using 100-ton universal testing machine through a system two point loads $(20 \mathrm{~cm}$ apart to a void crushing of concrete) using steel beams as shown in Fig. (3). Beams having length bigger than 160 were tested under ten-ton machine capacity as shown in Fig (3). Strains were measured both mechanically using extensometer and electrically using electrical strain gauges. Mechanical reading were taken by mechanical extensometer having gauge length $20 \mathrm{~cm}$ with an accuracy of $.01 \mathrm{~mm}$ to measure the longitudinal concrete strains at pre-selected two points at center across the web of each beam, as illustrated in Fig. (1). Electrical strain gauges were used to measure the strain in the reinforcing steel at center and Fig. (1) shows the position of the strain gauge. The mid span deflection was measured by dial gauge. To check the equipments, and the testing setup the beam was loaded to about one third of the calculated flexural cracking load and then unloaded. The reading of all strains and dial gauges were recorded for zero. The load was then applied in increments until the beam failed. During testing, the cracks were marked after each load increment. A cross line indicated the extent of propagation and the load was written near the line. After collapse the beams were photographed.

\section{6- EXPERIMENTAL INVESTIGATION}

\section{6-1 Mode of Failure and Pattern of Cracks}

The common pattern of cracks developed in some tested beams of each group is shown in Fig. (2) and Fig (3). When the beam was loaded, flexural cracks initiated in tension side of the tested beam in pure bending zone. As the applied load increased the flexural cracks extended upwards the compression zone. Also some inclined cracks have been appeared at shear zone of some tested beams depend on the shear span to depth ratio. As the load increased, existing flexural cracks continued widening till fialure. Regarding to the pattern of cracks for all tested beams, it is obviously that, the concrete strength, the beam span to depth ratio, shear span to depth ratio, the section reinforcement ( $\mu, \mu^{\prime}$, the side reinforcement, and \% of stirrups) and the existence of flange in tension zone have the significant effect on the crack propagation upward the beam web and through the beam length. The number of the cracks and its proportion through the web decreases as the concrete strength, percentage of main steel and the beam depth increase. All beams failed in flexural failure except tested beams numbers six and ten, which failed locally underneath load application. 

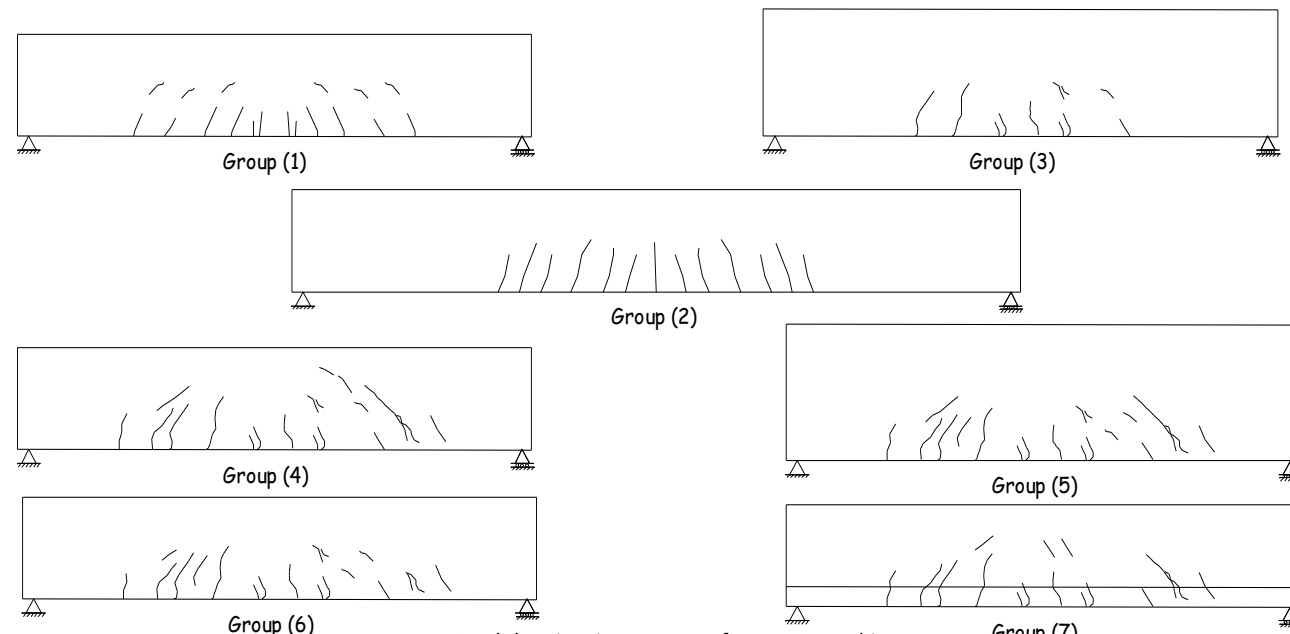

Fig (2): Crack pattern of some tested beams
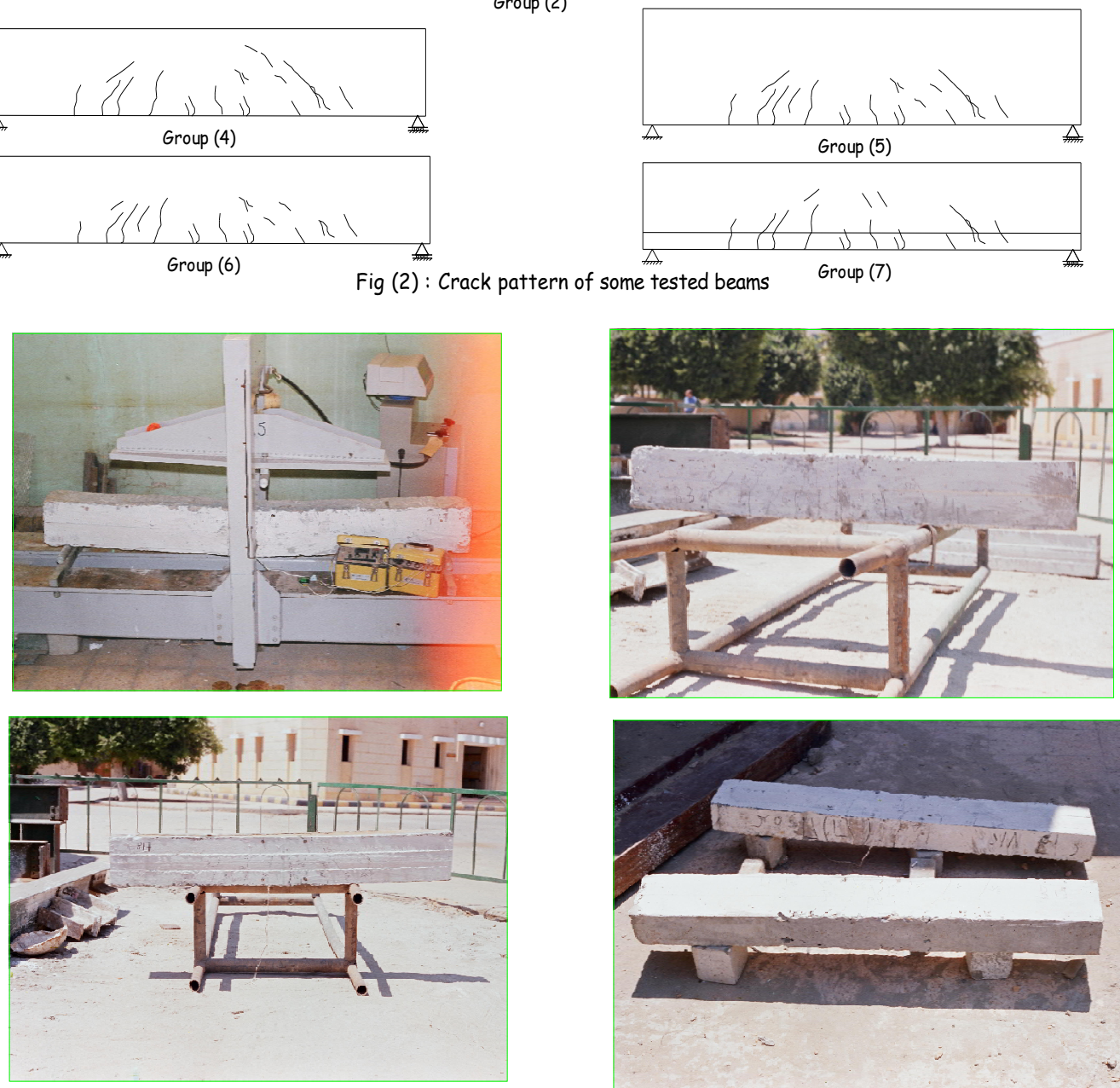

Fig (3) : Some photos of tested beams and the testing machine

\section{6-2 Cracking and Ultimate Loads}

The values of cracking $\left(\mathrm{P}_{\mathrm{cr}}\right)$ and ultimate loads $\left(\mathrm{P}_{\mathrm{u}}\right)$ for reinforced concrete tested beams are indicated in Table (5), also the ratio between them $\left(\mathrm{P}_{\mathrm{cr}} / \mathrm{P}_{\mathrm{u}}\right)$ is indicated. From this Table, the effect of various investigated parameters (the concrete strength, the beam span to depth Ratio, shear span to depth ratio, the section reinforcement $(\mu, \mu$ the side reinforcement, and $\%$ of stirrups and the existence of flange in tension zone) on both the appearance of first crack and the ultimate failure load is declared. 
Obviously, as the concrete strength (group 1), beam depth (group two), and the percentage of main steel (group four) increases, the first visible crack load and the ultimate failure load of these tested beams increase too. The side reinforcement (group 6) has significant effect on both cracking load and ultimate failure load. The ratio between the cracking and ultimate loads $\left(\mathrm{P}_{\mathrm{cr}} / \mathrm{P}_{\mathrm{u}}\right)$ resulted from tested beams ranges from $23 \%$ to $38 \%$.

Table (5): The experimental values of cracking, first yielding of steel and ultimate loads for all tested beams.

\begin{tabular}{|c|c|c|c|c|c|c|c|c|c|c|c|}
\hline $\begin{array}{l}\sum^{2} \\
\circ \\
0 \\
0 \\
\text { o }\end{array}$ & 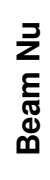 & 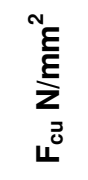 & $\mathbf{L} / \mathbf{d}$ & $\mathbf{L} / \mathbf{a}$ & $\boldsymbol{\mu}$ & $\mu^{\prime} / \mu$ & 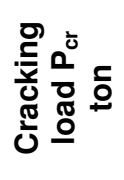 & $\begin{array}{l}\text { 윰 } \\
\frac{0}{0} \\
\frac{0}{0} \\
\frac{0}{2}\end{array}$ & 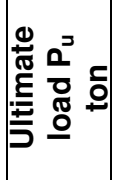 & $\frac{0^{3}}{0^{\frac{j}{3}}}$ & $\frac{a^{3}}{a^{7}}$ \\
\hline \multicolumn{12}{|c|}{ Group one: Effect of compressive strength } \\
\hline \multirow{5}{*}{1} & 1 & 27.5 & 8.4 & 3.6 & 0.73 & 0.65 & 1.2 & not work & 4.5 & 0.267 & ---- \\
\hline & 2 & 35 & 8.4 & 3.6 & 0.73 & 0.65 & 1.2 & $3 . .2$ & 4.5 & 0.267 & 0.71 \\
\hline & 3 & 55 & 8.4 & 3.6 & 0.73 & 0.65 & 1.3 & 3.5 & 4.8 & 0.27 & 0.73 \\
\hline & 4 & 70 & 8.4 & 3.6 & 0.73 & 0.65 & 1.6 & 4 & 5.5 & 0.3 & 0.72 \\
\hline & 5 & 78 & 8.4 & 3.6 & 0.73 & 0.65 & 1.75 & 4.1 & 5.5 & 0.32 & 0.75 \\
\hline \multicolumn{12}{|c|}{ Group two: Effect of beam length } \\
\hline \multirow{4}{*}{2} & 6 & 35 & 5.3 & 2.1 & 0.46 & 0.56 & 1.2 & not yield & 4.5 & 0.267 & not yield \\
\hline & 2 & 35 & 8.4 & 3.6 & 0.73 & 0.65 & 1.2 & $3 . .2$ & 4.5 & 0.267 & 0.71 \\
\hline & 7 & 35 & 11 & 5 & 0.73 & 0.65 & 0.9 & 2.4 & 3.3 & 0.27 & 0.72 \\
\hline & 8 & 35 & 16.3 & 7.5 & 0.73 & 0.65 & 0.50 & 1.42 & 2 & 0.25 & 0.71 \\
\hline \multicolumn{12}{|c|}{ Group three: Effect of beam depth } \\
\hline \multirow{3}{*}{3} & 2 & 35 & 8.4 & 3.6 & 0.73 & 0.65 & 1.2 & $3 . .2$ & 4.5 & 0.267 & 0.71 \\
\hline & 9 & 35 & 8.4 & 3.6 & 0.47 & 0.65 & 2.25 & $\begin{array}{l}\text { not } \\
\text { work }\end{array}$ & 7 & 0.32 & --- \\
\hline & 10 & 35 & 8.4 & 3.6 & 0.34 & 0.65 & 2.5 & not yield & 8.5 & 0.29 & ---- \\
\hline \multicolumn{12}{|c|}{ Group four: Effect of beam tension reinforcement } \\
\hline \multirow{3}{*}{4} & 2 & 35 & 8.4 & 3.6 & 0.73 & 0.65 & 1.2 & $3 . .2$ & 4.5 & 0.267 & 0.71 \\
\hline & 11 & 35 & 8.4 & 3.6 & 1.1 & 0.42 & 1.7 & $\begin{array}{l}\text { not } \\
\text { work }\end{array}$ & 6.75 & 0.25 & ---- \\
\hline & 12 & 35 & 8.4 & 3.6 & 1.46 & 0.32 & 2.0 & $\begin{array}{l}\text { not } \\
\text { work }\end{array}$ & 8 & 0.25 & ---- \\
\hline \multicolumn{12}{|c|}{ Group five: Effect Beam stirrups } \\
\hline \multirow{3}{*}{5} & 2 & 35 & 8.4 & 3.6 & 0.73 & 0.65 & 1.2 & $3 . .2$ & 4.5 & 0.267 & 0.71 \\
\hline & 13 & 35 & 8.4 & 3.6 & 0.73 & 0.65 & 1.2 & $\begin{array}{c}\text { not } \\
\text { work }\end{array}$ & 4.5 & 0.267 & ---- \\
\hline & 14 & 35 & 8.4 & 3.6 & 0.73 & 0.65 & 1.2 & $\begin{array}{c}\text { not } \\
\text { work }\end{array}$ & 4.5 & 0.267 & --- \\
\hline \multicolumn{12}{|c|}{ Group six: effect of beam side reinforcement } \\
\hline \multirow{3}{*}{6} & 15 & 35 & 8.4 & 3.6 & 0.47 & 0.65 & 2 & 5.6 & 8.5 & 0.23 & 0.66 \\
\hline & 16 & 35 & 8.4 & 3.6 & 0.71 & 0.32 & 3 & $\begin{array}{l}\text { not } \\
\text { work }\end{array}$ & 12 & 0.25 & ----- \\
\hline & 17 & 35 & 8.4 & 3.6 & 0.71 & 0.32 & 3.5 & 12.75 & 14.5 & 0.24 & 0.87 \\
\hline \multicolumn{12}{|c|}{$\begin{array}{c}\text { Group seven: effect of Beam flange (the flange has } 6 \varnothing 6 \mathrm{~mm} / \mathrm{m}^{\prime} \text { stirrups, and its each wing has } \\
\text { one bar } 6 \mathrm{~mm} \text { ) }\end{array}$} \\
\hline \multirow{2}{*}{7} & 18 & 2.5 & 8.4 & 3.6 & 0.94 & 0.65 & 3 & 7.2 & 7.75 & 0.38 & 0.92 \\
\hline & 19 & 3.33 & 8.4 & 3.6 & 0.94 & 0.65 & 3 & $\begin{array}{l}\text { not } \\
\text { work }\end{array}$ & 7.75 & 0.38 & ---- \\
\hline
\end{tabular}




\section{6-3 Deflection of the Tested Beams}

Atypical experimental load versus measured deflection curve, for all simply supported reinforced flexural tested beams are plotted in Figs. (4) to (22).

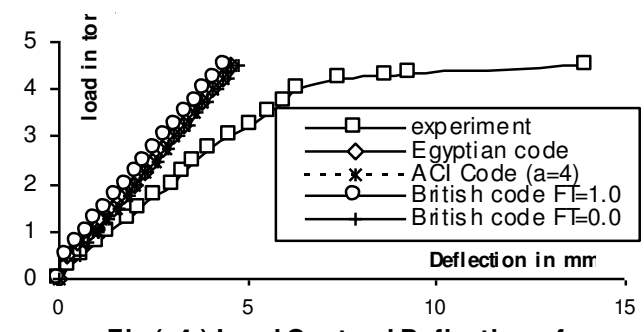

Fig ( 4 ) Load-Centeral Deflection of Tested Beam(1)of group(1)

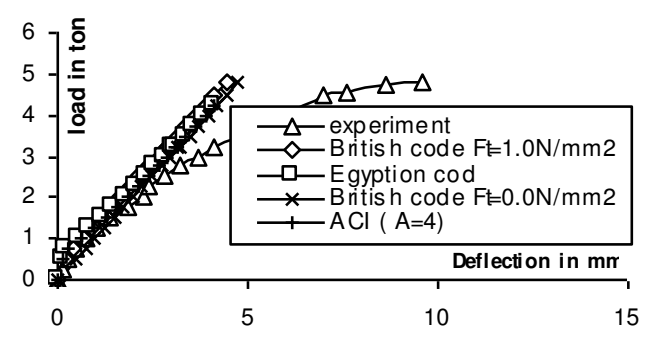

Fig ( 6 ) Load-Central Deflection of Tested Beam (3) of Group (1)

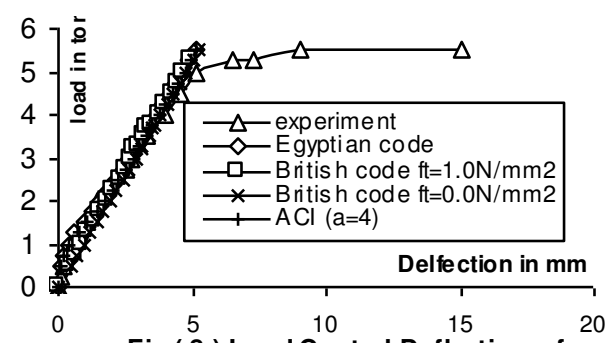

Fig ( 8 ) Load-Central Deflection of Tested Beam (5) of group(2)

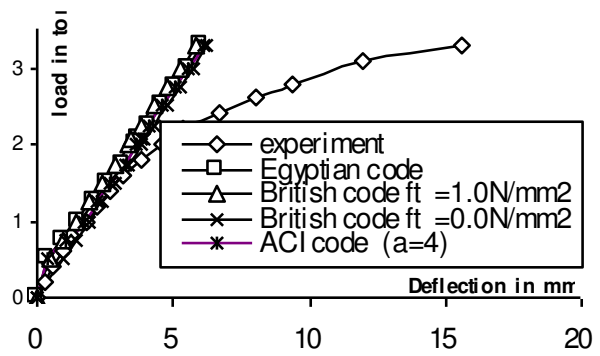

Fig ( 10 ) load-Central Deflection of tested beam (7) Of Group (2)

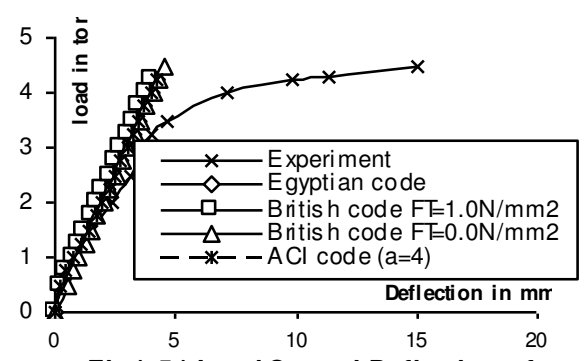

Fig ( 5 ) Load-Central Deflection of tested beam (2) of Group(1)

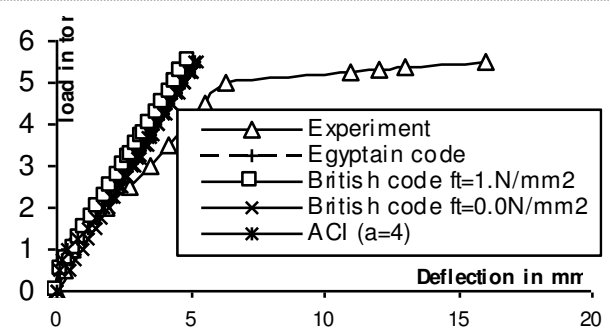

Fig ( 7 ) Load-Central Deflection of Tested Beam (4) of Group(1)

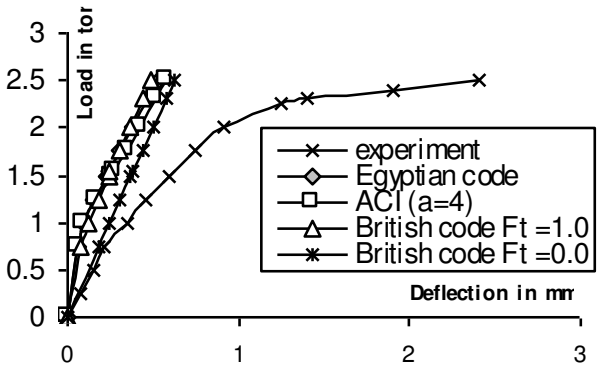

Fig ( 9 )Load central Deflection Of Beam Tested (6) Of Group(2)

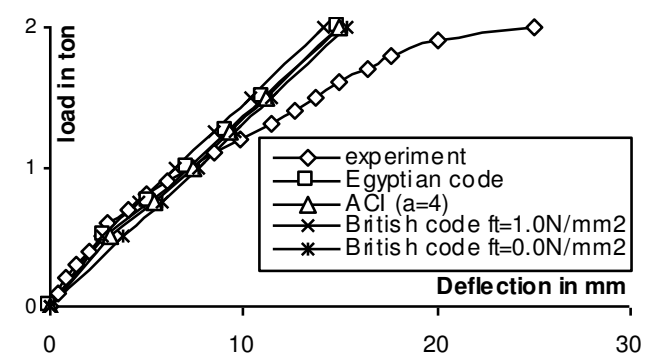

Fig ( 11 ) load-Central Deflection of tested beam(8) of group(2) 
Also these curves showed the comparisons between the measured and the calculated values of deflections. Generally, the characteristic stages of these experimental curves can be roughly divided into three intervals: elastic stage, cracking propagation and the plastic stage. Two major material effects, cracking of concrete and plasticity of reinforcement and compression of concrete, cause the nonlinear response. Also, the deflection values of these tested beams were depending on the flexural rigidity, the percentage of stirrups, and shear span to depth ratio and side reinforcement of these tested beams, such as it was established before $[9,10,18-21]$.

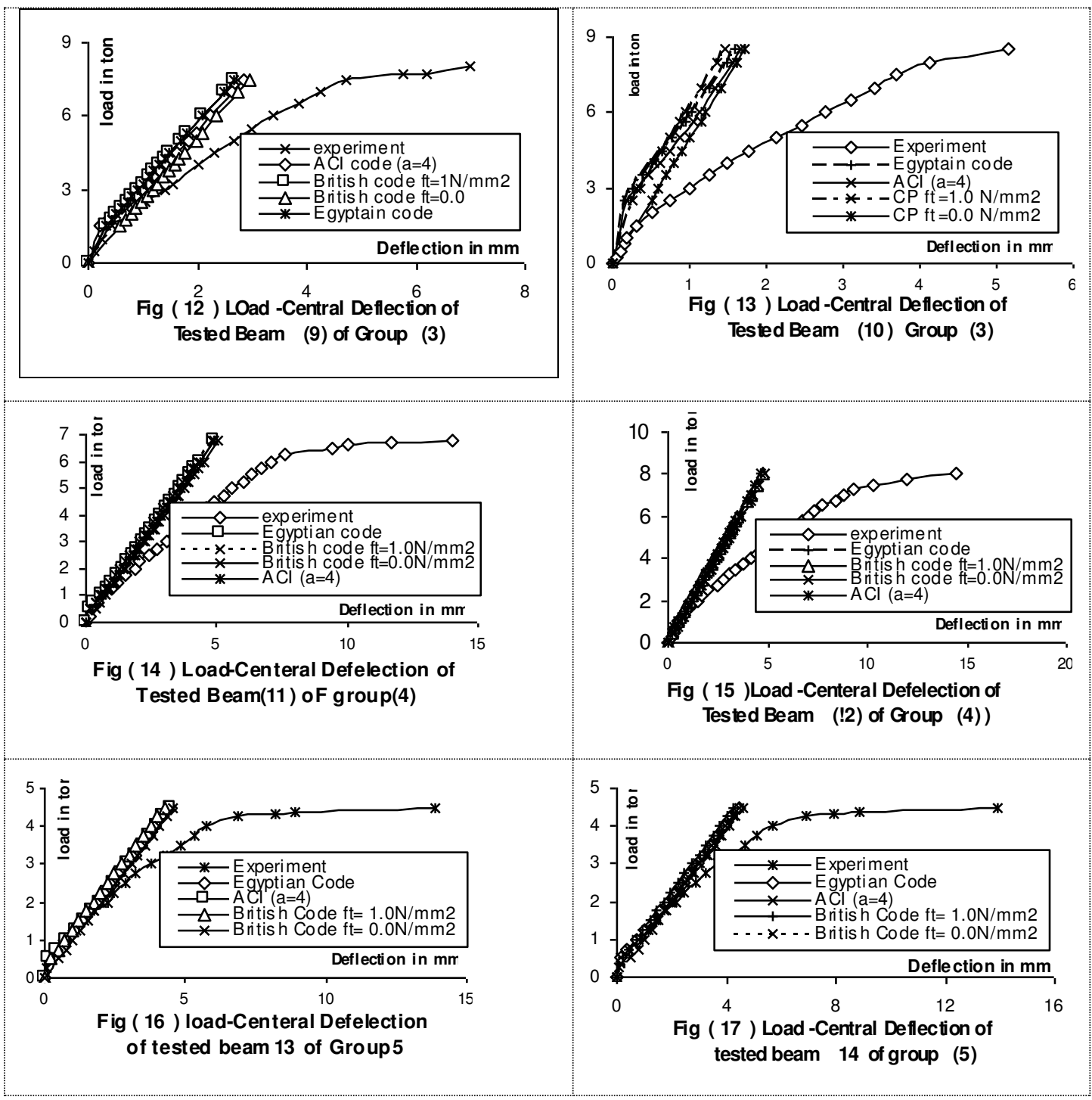




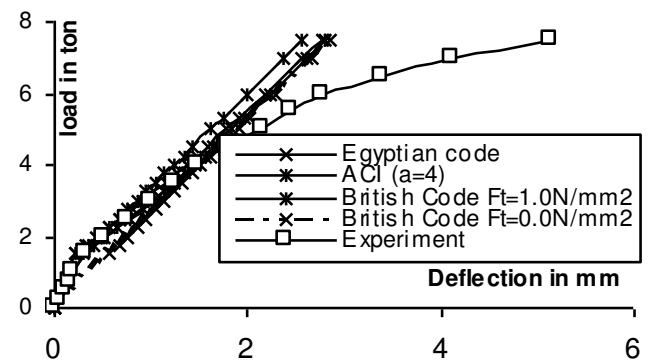

Fig ( 18 )Load -Central Deflection of Tested Beam (15) Group (6)

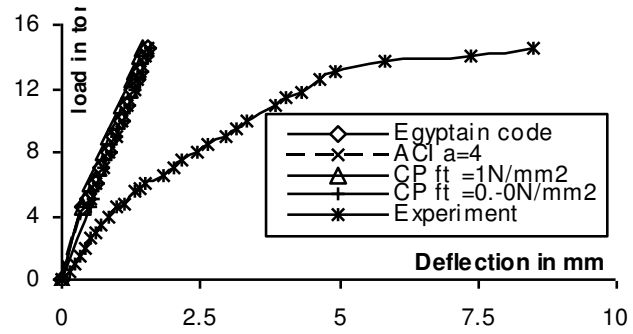

Fig (20) load-Central Deflection of tested beam (17) of Group (7)

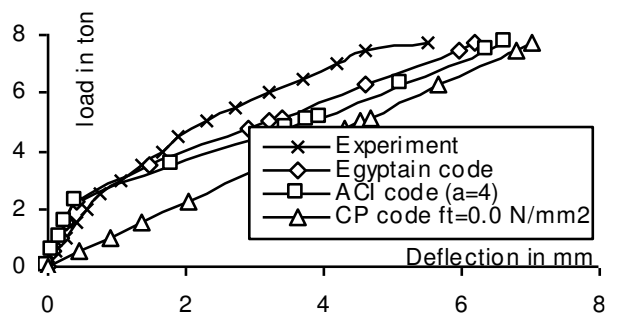

Fig ( 22 ) load-Central Deflection of tested Beam 19 of Group7
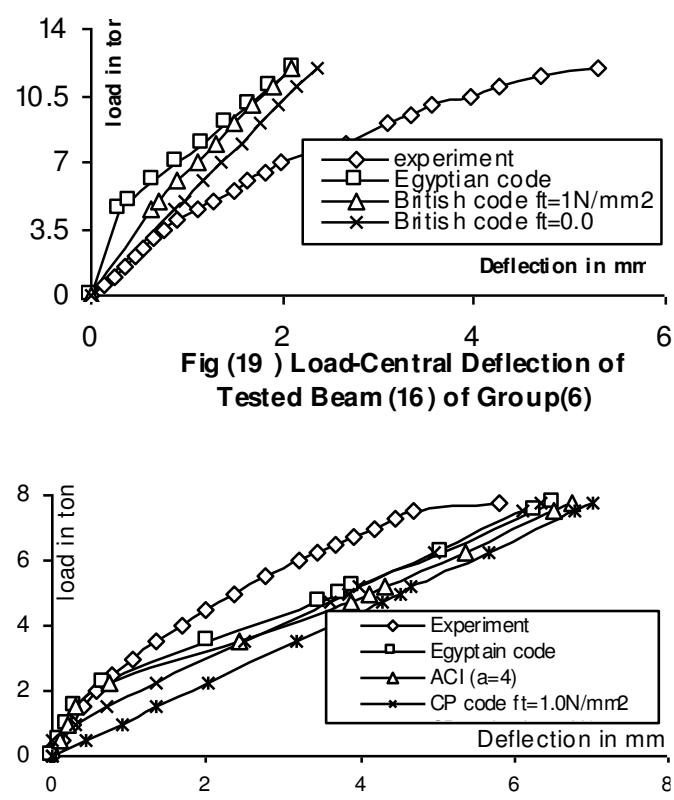

Fig ( 21 ) load-Central Deflection of tested beam (8) of Group(7)

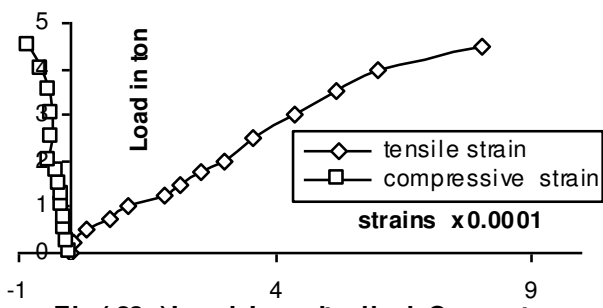

Fig ( 23 ) Load-Longitudinal Concrete Strains at Center at Extreme Fibers of Beam(1) of Group(1)

\section{6- 4 Concrete Strains}

Figures (23) to (37) show the measured concrete strains at mid span along the web at two positions; one closed the compression zone and the other was closed to the tension zone for all tested beams. These curves reveal a similar behavior of the overall behavior of the tested beams. For all tested beams, the maximum concrete compressive strain at failure does not reached the ultimate concrete strain $(0.003$ as recommended by the Egyptian code).

\section{6-5 Strains in Main steel}

Unfortunately not all steel strain gauges of the tested beams worked satisfactorily. Figures (38) to (42) show the measured main steel strains at the center of the tested beam of each group, which worked adequately. It can be seen form these curves that all steel yielded before the tested beam reached to the ultimate bending capacity and the yield load depends on the percentage of main steel, as the percentage of main steel increases the yield load decreases. 


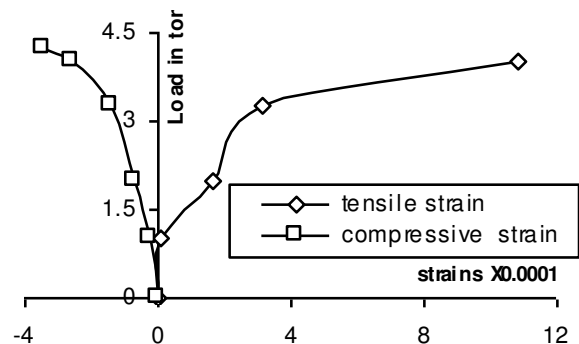

Fig (24) Load Longitudinal concerte strains at central of extreme fibers of tested beam (2) of group 1

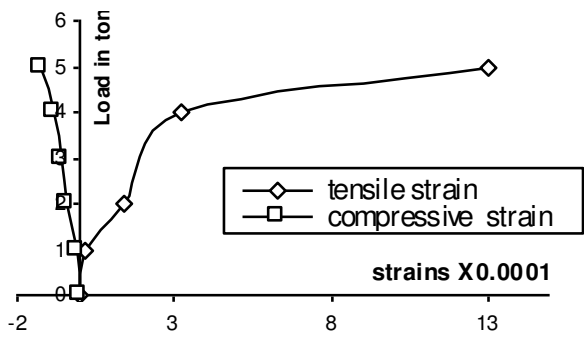

Fig ( 26 ) Load Longitudinal Concrete Strains at Center, at Extreme Fibers of Beam(4) of Group(1)

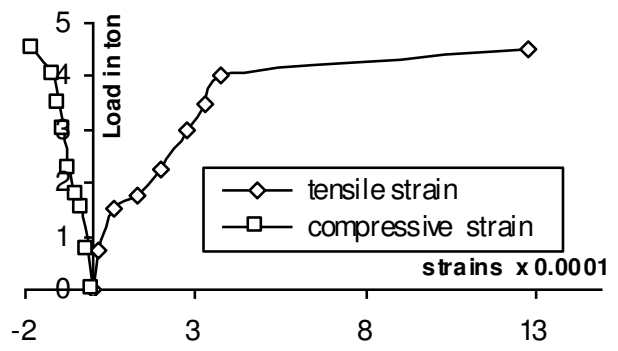

Fig ( 25 ) Load Longitudinal Concrete Strains at Central at Extreme Fibers of Tested Beam (3) of Group(1)

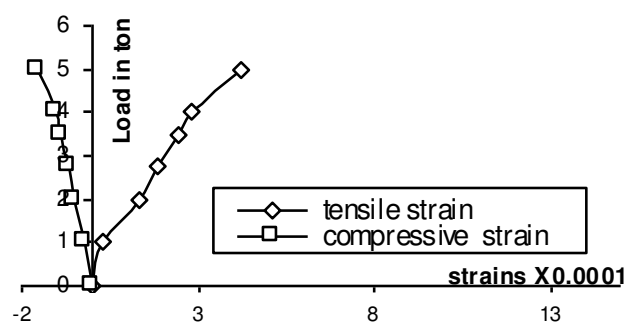

Fig ( 27 )Load Longitudinal concrete strains at center at extreme fibers of Beam (5) of Group (1)

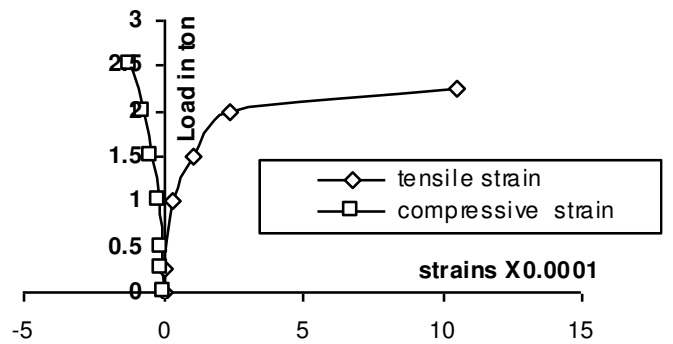

Fig (28) Load Longitudinal Concrete Strains at Center at Exterme Fiber of Beam6 of Group2

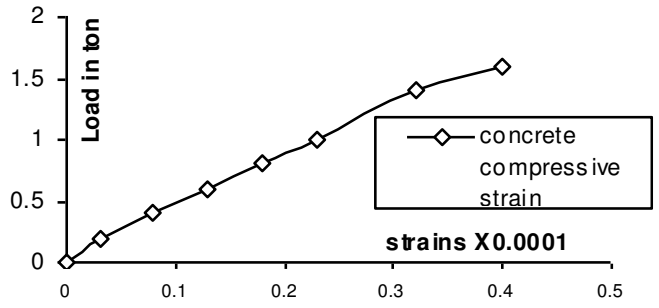

Fig (29)Load long itudinal Strains at center at extreme fibers of beam (7) of Group (2) 


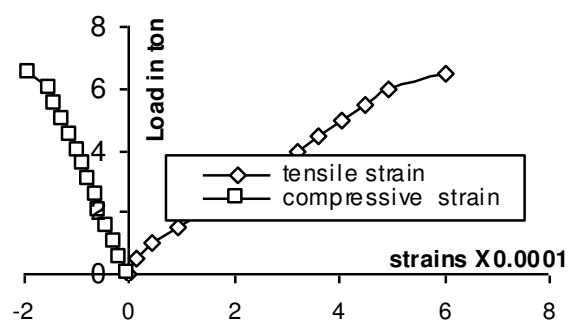

Fig (30 )Load Longitudinal oncrete

Strains at center at exterme fiber of beam(11) of Gourp(4)

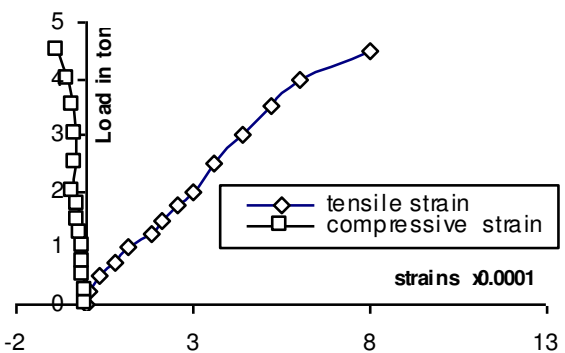

Fig ( 32 ) Load Longitudinal Concrete at center at extreme fiber of beam 13 of group5

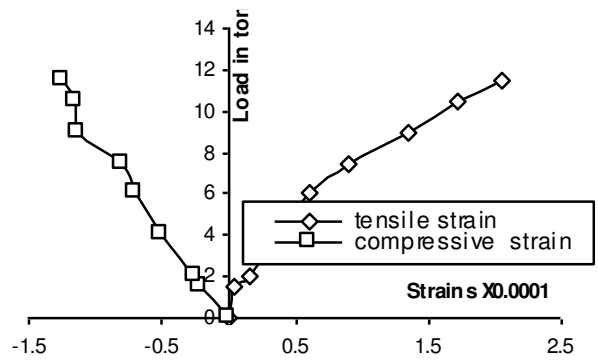

Fig (34) load Longitudinal concrete Strains at Center at Extreme Fibers

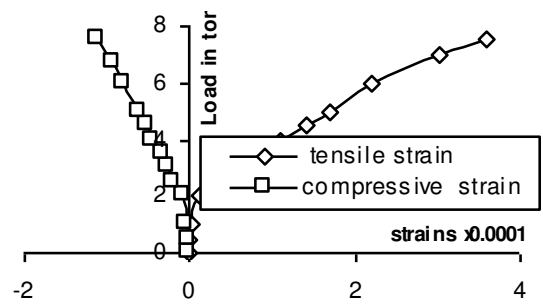

Fig ( 36 )Load Longitudinal concrete strains at center at extreme fibers of Beam 18 of Group 7

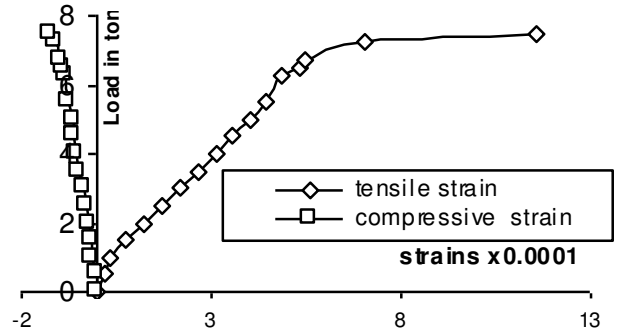

Fig (31 )Load Longitudinal Concrete Strain sat center at extreme fiber of beam 12 of Group 4

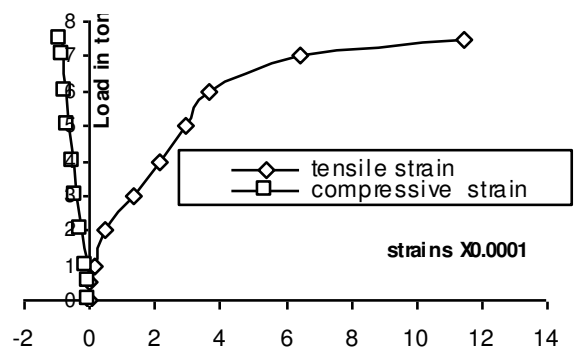

Fig (33) Load Longtitudinal Concret $\epsilon$ Strains at Center at Extrem Fiber of of beam 15 of Group 6

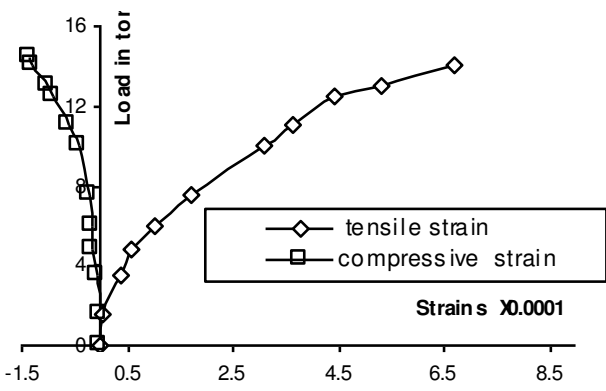

Fig (35 )Load Longitudinal Concrete Strains at Center at Extreme Fiber of Beam 17 Group 6

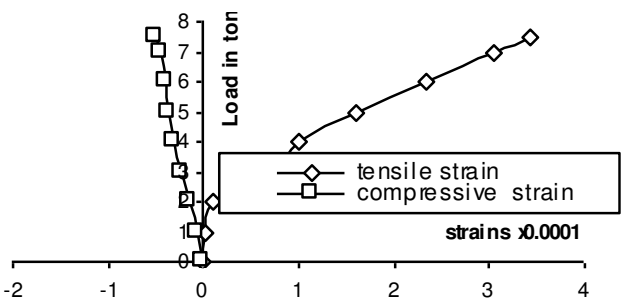

Fig ( 37 )Load Longitudnal Concrete Strains at Center at Extreme Fibers of Beam 19 Group 7 

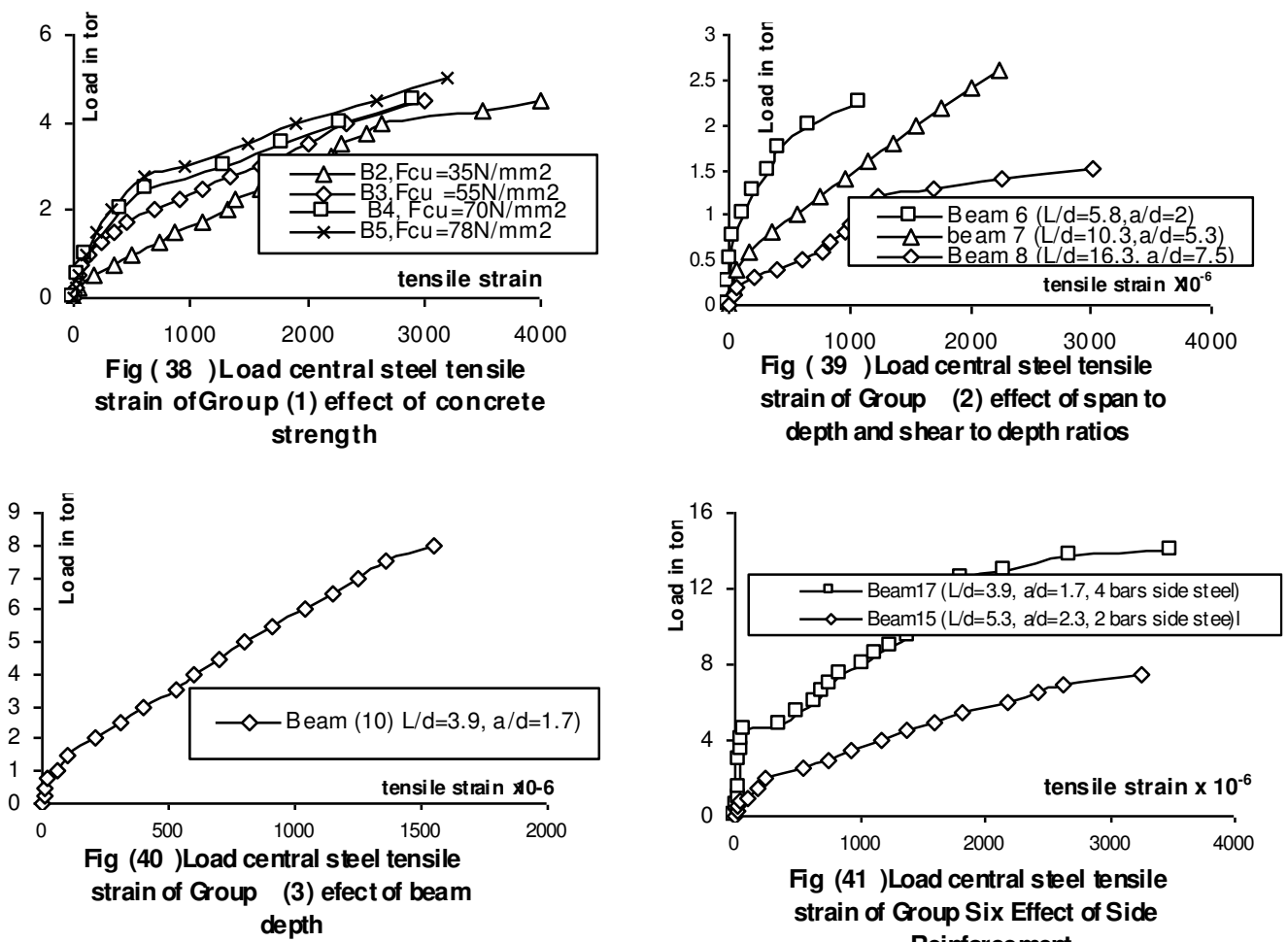

Fig (41)Load central steel tensile strain of Group Six Effect of Side Reinforcement

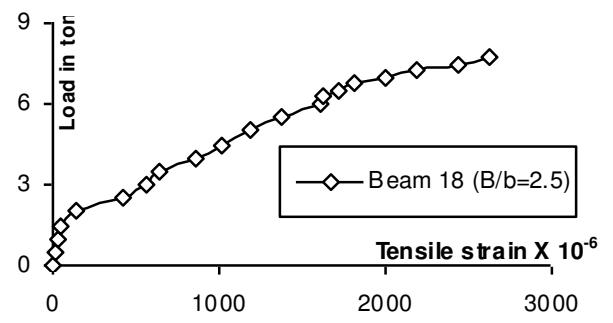

Fig ( 42 )Load Central Tensile Steel Strain of Group7 (Efffet of flangф

\section{7- SERVICEABILITY LIMIT STATE CALCULTION}

\section{7-1 Deflections at 0.67 Ultimate Failure Load}

A summary of predicted behavior of all tested beams using codes of practices deflection equation is given in table (6). Also compression between the analytical experimental values of deflection is given. The service load has been taken as the experimentally measured one of $0.67 \mathrm{P}_{\mathrm{u}}$ (ultimate failure load). In this table there is five values of deflection for each tested beam at $0.67 \mathrm{P}_{\mathrm{u}}$ were computed. The first and second computed values was based on $\mathrm{I}_{\mathrm{e}}$ with $(\mathrm{a}=3$ and $\mathrm{a}=4)$, the third computed value of deflection was based on $\mathrm{I}_{\text {cr. }}$ The fourth and the fifth values of computed deflection were based on moment curvature [cp110 code] with two values of $\mathrm{ft}\left(1 \mathrm{~N} / \mathrm{mm}^{2}\right.$ and 0.0$)$. 
Table (6) :Comparison between the Predicted Experimental Deflections at Load of $0.67 \mathrm{P}_{\mathrm{u}}$ with the Analytical Values.

\begin{tabular}{|c|c|c|c|c|c|c|c|c|c|c|c|c|c|c|c|}
\hline \multirow{3}{*}{ 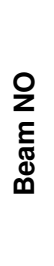 } & \multirow{3}{*}{ 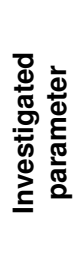 } & \multicolumn{3}{|c|}{$\begin{array}{l}\text { Experimental } \\
\text { values ton }\end{array}$} & \multicolumn{6}{|c|}{$\begin{array}{l}\text { Deflection at0.67 of ultimate failure load } \\
\qquad \mathrm{mm}\end{array}$} & \multicolumn{5}{|c|}{$\%$ of $\delta_{\text {calculated }} / \delta_{\exp }$} \\
\hline & & \multirow{2}{*}{ 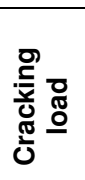 } & \multirow{2}{*}{ 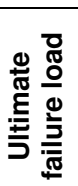 } & \multirow{2}{*}{ 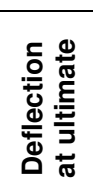 } & \multirow{2}{*}{ 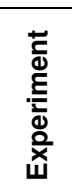 } & \multicolumn{5}{|c|}{ Calculated values } & \multicolumn{3}{|c|}{$\mathrm{ACl}, \mathrm{ECO}$} & \multicolumn{2}{|c|}{$\begin{array}{l}\mathrm{CP} \\
\mathrm{N} / \mathrm{mm}^{2}\end{array}$} \\
\hline & & & & & & - & - 危 & $\stackrel{0}{0}$ & 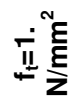 & 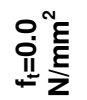 & - & - 君 & $\stackrel{2}{0}$ & $\stackrel{T}{\longleftarrow}$ & 움 \\
\hline & $\mathrm{F}_{\mathrm{cu}}$ & \multicolumn{14}{|c|}{ Effect of concrete compressive strength } \\
\hline 1 & 27. & 1.2 & 4.5 & 13.95 & 4.3 & 2.96 & 3.03 & 3.05 & 2.83 & 3.14 & 69 & 70.6 & 71 & 66 & 73 \\
\hline 2 & 8.4 & 1.2 & 4.5 & 15.0 & 3.97 & 2.84 & 2.94 & 2.98 & 2.74 & 3.05 & 71.5 & 74 & 75 & 69 & 76 \\
\hline 3 & 55 & 1.3 & 4.8 & 9.6 & 4.0 & 2.83 & 3 & 3.1 & 2.84 & 3.17 & 71 & 75 & 77.5 & 73 & 79 \\
\hline 4 & 70 & 1.6 & 5.5 & 16 & 4.3 & 3.12 & 3.34 & 3.46 & 3.12 & 3.51 & 72 & 77 & 80.4 & 72 & 81 \\
\hline 5 & 78 & 1.75 & 5.5 & 15 & 4.3 & 3.06 & 3.3 & 3.46 & 3.12 & 3.51 & 71 & 76 & 80 & 72 & 81 \\
\hline & & \multicolumn{14}{|c|}{ Effect of beam length } \\
\hline 6 & 5.3 & 0.8 & 2.5 & 2.9 & 0.69 & .133 & .133 & .553 & .347 & .591 & 19 & 19 & 59 & 50 & 75 \\
\hline 2 & 8.38 & 1.2 & 4.5 & 15.0 & 3.97 & 2.84 & 2.94 & 2.98 & 2.74 & 3.05 & 71.5 & 74 & 75 & 69 & 76 \\
\hline 7 & 10.3 & 0.9 & 3.3 & 17 & 5.4 & 3.84 & 4 & 4.07 & 3.7 & 4.175 & 71 & 74 & 75 & 68 & 77 \\
\hline 8 & 16.3 & 0.50 & 2 & 25 & 11.5 & 9.36 & 9.75 & 9.94 & 8.97 & 10.19 & 81 & 85 & 86 & 78 & 88 \\
\hline & $\mathrm{L} / \mathrm{d}$ & \multicolumn{14}{|c|}{ Effect of beam depth } \\
\hline 2 & 8.4 & 1.2 & 4.5 & 15.0 & 3.97 & 2.84 & 2.94 & 2.98 & 2.74 & 3.05 & 71.5 & 74 & 75 & 69 & 76 \\
\hline 9 & 5.4 & 2.25 & 7 & $\begin{array}{l}5.8 \\
\end{array}$ & 2.42 & 1.45 & 1.61 & 1.75 & 1.51 & 1.79 & 60 & 66 & 72 & 63 & 74 \\
\hline 10 & 3.9 & 2.5 & 8.5 & 5.13 & 2.5 & 0.59 & .713 & 1.01 & .857 & 1.12 & 23 & 28 & 44 & 34 & 45 \\
\hline & $\mu^{\prime} / \mu$ & \multicolumn{14}{|c|}{ Effect of $\%$ of main steel reinforcement } \\
\hline 2 & 0.6 & 1.2 & 4.5 & 15.0 & 3.97 & 2.84 & 2.94 & 2.98 & 2.74 & 3.05 & 71.5 & 74 & 75 & 69 & 76 \\
\hline 11 & 1 & 1.7 & 6.75 & 14 & 4.9 & 3.23 & 3.26 & 3.27 & 3.163 & 3.37 & 66 & 66.5 & 66.5 & 64. & 69 \\
\hline 12 & 0.3 & 2.0 & 8 & 14.5 & 6 & 3.55 & 3.57 & 3.57 & 3.508 & 3.7 & 59 & 59 & 59.5 & 58 & 62 \\
\hline & St* & \multicolumn{14}{|c|}{ Effect of $\%$ of stirrups } \\
\hline 2 & 8.4 & 1.2 & 4.5 & 15.0 & 3.97 & 2.84 & 2.94 & 2.98 & 2.74 & 3.05 & 71.5 & 74 & 75 & \begin{tabular}{|l|}
69 \\
\end{tabular} & 76 \\
\hline 13 & 10 & 1.2 & 4.5 & 14 & 3.8 & 2.84 & 2.94 & 2.98 & 2.74 & 3.05 & 74.7 & 77 & 78 & 72 & 80 \\
\hline 14 & 12 & 1.2 & 4.5 & 13.9 & 3.65 & 2.84 & 2.94 & 2.98 & 2.74 & 3.05 & 77.8 & 80.5 & 81.6 & 75 & 83 \\
\hline & Shi* & \multicolumn{14}{|c|}{ Effect of side reinforcement } \\
\hline 15 & 2 & 2 & 8.5 & 5.15 & 2.5 & 1.61 & 1.76 & 1.88 & .776 & .944 & 64 & 70.4 & 75 & 30 & 82 \\
\hline 16 & 2 & 3 & 12 & 5.3 & 2.65 & .95 & 1 & 1.05 & .488 & .601 & 36 & 37.7 & 39.6 & 22 & 35 \\
\hline 17 & 4 & 3.5 & 14.5 & 8.5 & 3.15 & 1.03 & 1.09 & 1.13 & .613 & .726 & 32 & 35 & 36 & 19 & 23 \\
\hline & $\mathrm{B} / \mathrm{b}$ & \multicolumn{14}{|c|}{ Effect of beam flange in tension } \\
\hline 18 & 2.5 & 3 & 7.75 & 5.88 & 2.4 & 3.92 & 4.3 & 4.55 & 3.99 & 4.67 & 163 & 179 & 189 & 166 & 194 \\
\hline 19 & $\begin{array}{l}3.3 \\
3\end{array}$ & 3 & 7.75 & 5.5 & 2.35 & 3.39 & 3.95 & 4.55 & 3.8 & 4.67 & 144 & 168 & 194 & 162 & 198 \\
\hline & & Beam & vestis & atex & erimer & 1 by ot & er auth & rs $(21$ & ) and a & lyzed ar & alytical & $y$ in $t$ & study & & \\
\hline & $\mu^{\prime} / \mu$ & & & & & & $\operatorname{ned}(2$ & (Effe & of shrir & gge steel & & & & & \\
\hline $\mathrm{C} 0$ & 0.0 & 1.1 & 4.5 & 5.75 & 3 & 1.41 & 1.49 & 1.55 & 1.33 & 1.54 & 0.47 & 0.5 & 0.52 & 0.4 & $=5$ \\
\hline & $\mathrm{B} / \mathrm{b}$ & & Nael $(2$ & Effec & ff the & esence & of the $f$ & nge in & nsion & e) $(\mathrm{a} / \mathrm{d}=$ & $2.7 \mu$ & $=1.4$ & $\mu^{\prime} / \mu$ & $=0.33)$ & \\
\hline $\mathrm{A} 1$ & 2 & 3.9 & 13.5 & 4.4 & 2.75 & 3.73 & 3.83 & 3.87 & 3.667 & 4.069 & 135 & 139 & 141 & 133 & 148 \\
\hline A2 & 3 & 4.2 & 13.5 & 4.22 & 2.6 & 3.45 & 3.7 & 3.87 & 3.47 & 4.069 & 133 & 142 & 149 & 133 & 156 \\
\hline A3 & 4 & 4.8 & 13.5 & 4.01 & 2.38 & 3.07 & 3.42 & 3.87 & 3.287 & 4.069 & 129 & \begin{tabular}{|l|}
144 \\
\end{tabular} & 162 & 138 & 171 \\
\hline $\mathrm{A} 4$ & 5 & 5.2 & 13.5 & 3.67 & 2.12 & 2.65 & 3.05 & 3.87 & 3.1 & 4.018 & 125 & \begin{tabular}{|l|}
144 \\
\end{tabular} & 179 & 146 & 189 \\
\hline
\end{tabular}


In Fig. (4) to Fig. (21) comparisons are presented for load deflection obtained experimentally and those obtained analytic using different values of $\mathrm{I}_{\mathrm{e}}$ (Ie for $\mathrm{a}=3, \mathrm{I}_{\mathrm{e}}$ for $\left.\mathrm{a}=4, \mathrm{I}_{\mathrm{cr}}\right)$ and $\mathrm{F}_{\mathrm{t}}\left(1.0,0.0 \mathrm{~N} / \mathrm{mm}^{2}\right)$. In general, it can be seen form that table, except for beams six and ten, which failed locally:

1. The solutions by $I_{e}$ with a power equal to 3 and 4 differed by a maximum of 5 percent for the considered investigated parameters. As one can demonstrate by calculation, results of these equations are not particularly sensitive to the exact power.

2. The solutions by $I_{e}$ (with $a=3$ ) and $I_{c r}$ (which represents the lower limit of moment of inertia) differed by a maximum 8 percent.

3. The solution based on calculation of $\mathrm{CP}$ [8] with $\mathrm{f}_{t}=1 \mathrm{~N} / \mathrm{mm}^{2}$ leads to the same or slight stiffer results compared with the solution based on the ACI [6].

4. The solution based on calculation of CP [8] with $\mathrm{f}_{t}=0.0 \mathrm{~N} / \mathrm{mm}^{2}$ (which ignored the tensile resistance of concrete in tension zone) leads to more flexible results compared with the solution based on $\mathrm{I}_{\mathrm{e}}$ of the ACI [6] equation. The percentage of difference depends on the studied parameters.

\section{7-2 Comparison between the Experimental Results and the Analytical Results}

Referring to table (6) the following can be drawn out:-

1-The Effect of Compressive Strength of concrete (First group $\mu^{\prime} / \mu=0.65$, $\mathrm{L} / \mathrm{d}=8.4, \mathrm{a} / \mathrm{d}=3.6$, no Shrinkage steel used, five different grades of concrete grades $(\mathrm{C} 275, \mathrm{C} 350, \mathrm{C} 550, \mathrm{C} 700, \mathrm{C} 780))$ : The approximate procedure of ACI or CP110 underestimates the computed deflections by $29 \%$ compared with the experimental values and it does not affected by the concrete grades. This underestimation may be due to the fact that the deflection equation of codes does not include the effect of shear deformation into consideration.

2-Effect of Beam Length (Second Group, $C 350, \mu^{\prime} / \mu=0.65$, no shrinkage steel used three different values of $\mathrm{L} / \mathrm{d}(8.4,10.7,16.75$ with a/d, 3.6, 5.6, 7.5)): The approximate procedure underestimates the computed deflections by values ranges "between" $29 \%$ to $19 \%$ depends on the $\mathrm{L} / \mathrm{d}$ and a/d ratios. As the $\mathrm{L} / \mathrm{d}$ and a/d increase the percentage of underestimation reduces, this may be due the effect of shear deformation reduces as the $\mathrm{a} / \mathrm{d}$ ratio increases.

3-Effect of Beam Depth (Third Group, C350, $\mu^{\prime} / \mu=0.65$, a $/ \mathrm{d}=3.6$, no shrinkage steel used, three different values of $\mathrm{L} / \mathrm{d}(8.4,5.3,4.0))$ : The approximate procedure seriously underestimates the computed deflection compared with that of the corresponding experimental values, as the $\mathrm{L} / \mathrm{d}$ decreases. This may be due to the fact that as the beam depth increases, the beam load bearing capacity increases too and consequently the shear deformation increases and this deformation was neglected in the approximate equations of codes lead to this result.

4-Effect of Unsymmetrical Steel Reinforcement of Cross Section (Group Four, C350, $\mathrm{L} / \mathrm{d}=8.4, \mathrm{a} / \mathrm{d}=3.6$, no Shrinkage steel used, Three different values $\mu^{\prime} / \mu$ are used $(0.65,0.42,0.32))$ : The approximate procedure seriously underestimates the computed deflection compared with corresponding experimental values, as the $\mu^{1} / \mu$ decreases. This may be due to the shrinkage of concrete. The use of unsymmetrical steel reinforcement results in a nonuniform strain distribution and usually the 
accompanying warping causes deflection in the same direction as those caused by loads for which the beam was designed and reinforced. To put it another way, shrinkage forces are axial in nature and cause some tension on the compression side of the member, and hence shrinkage forces and loads are not resisted in the same way by a cracked transformed section.

5-The Effect of The percentage of Stirrups (Fifth Group C350, $\mu^{\prime} / \mu=0.65$, $\mathrm{L} / \mathrm{d}=8.4, \mathrm{a} / \mathrm{d}=3.6, \mathrm{C} 35$, no Shrinkage steel used, where three different arrangements of stirrups are used (see table (1)): The codes of practice's equations underestimates the computed defection values compared with the experimental measured values (the reduction values ranges between $(29 \%$ to $22 \%)$. The underestimation values decreases as the percentage of stirrups increases. This may be due to the resistance to shear deformation increases as the percentage the stirrups increase too.

6- Effect of Side Reinforcement (Sixth Group has two values of $\mu^{\prime} / \mu(0.65,0.33)$, L/d $(5,4,4)$, a/d $(2.3,1.76)$, Shrinkage steel was used and C35): It can be seen from table (6), as the ratio of $\mathrm{L} / \mathrm{d}$ and $\mathrm{a} / \mathrm{d}$ increase, the percentage of overestimation increases too independents on the percentage of side reinforcement increases.

7- Effect of Existence of Flange in Tension Zone (Seventh group C350, $\mu^{\prime} / \mu=$ $0.65, \mathrm{~L} / \mathrm{d}=8.4, \mathrm{a} / \mathrm{d}=3.6$, no Shrinkage steel used, two different values of $\mathrm{B} / \mathrm{b}(2.5,3.3)$. The codes of practice's equations for deflections overestimate the computed deflections compared with the experimental values. ACI and CP110 [6, 8] overestimate the deflection by average values of $112 \%$ and 79 respectively. This is attributable to the presence of the flange, actually it resists part of shear and bending deformations as well as the approximate procedure does not include the shear rigidity into consideration. Also, approximate procedure calculation shows that the neutral axis lies out side the flange, which means that $I_{c r}$ depends on the part of web as compression zone and the steel reinforcement of the flange only. The percentage of overestimation of CP110 is lesser than the percentage of overestimation of ACI; this due the CP110 includes the effect of tension stiffening of concrete at service limit in the calculation of deflection.

\section{7-3 Steel Stress at 0.67 Ultimate Failures Load}

As it was shown above, the British bridge code BS 5400 [8] gives stress limitations in the steel reinforcement. A summary of the predicted steel stress based on the elastic theory using equation (1) at 0.67 ultimate failure load with $I_{e}$ (with a=3,or 4=4) or $I_{c r}$. Also the stress in steel can be calculated as given above based on the curvature with $\left(\mathrm{ft}=1 \mathrm{n} / \mathrm{mm}^{2}\right.$ or $\left.\mathrm{ft}=0.0 \mathrm{~N} / \mathrm{mm}^{2}\right)$.

$$
F_{s}=\frac{M_{a}}{I_{e}}(d-z)
$$

Where $F_{s}, M_{a}, d, I_{e}$ and $z$ are steel stress, maximum moment in member at stage at which the deflection is being computed, effective depth, effective moment of inertia, and the depth of compression zone. Table (7) gives comparison between the measured and the computed values of steel stress for the worked strain gauges only. Based on this compression, approximate procedure gives a reasonable prediction of stresses in steel at service limit load. The stresses are underestimated by $10 \%$ for rectangular sections of grade C350 (except model six which failed locally) and are overestimated in rectangular sections made of high strength concrete grades (C550, C700, C780) and $\mathrm{T}$ - section made of concrete grade $\mathrm{C} 350$. 
Table (7): Comparison Between the Predicted Experimental Steel Stress at Load of $0.67 \mathrm{P}_{\mathrm{u}}$ with the Analytical Values.

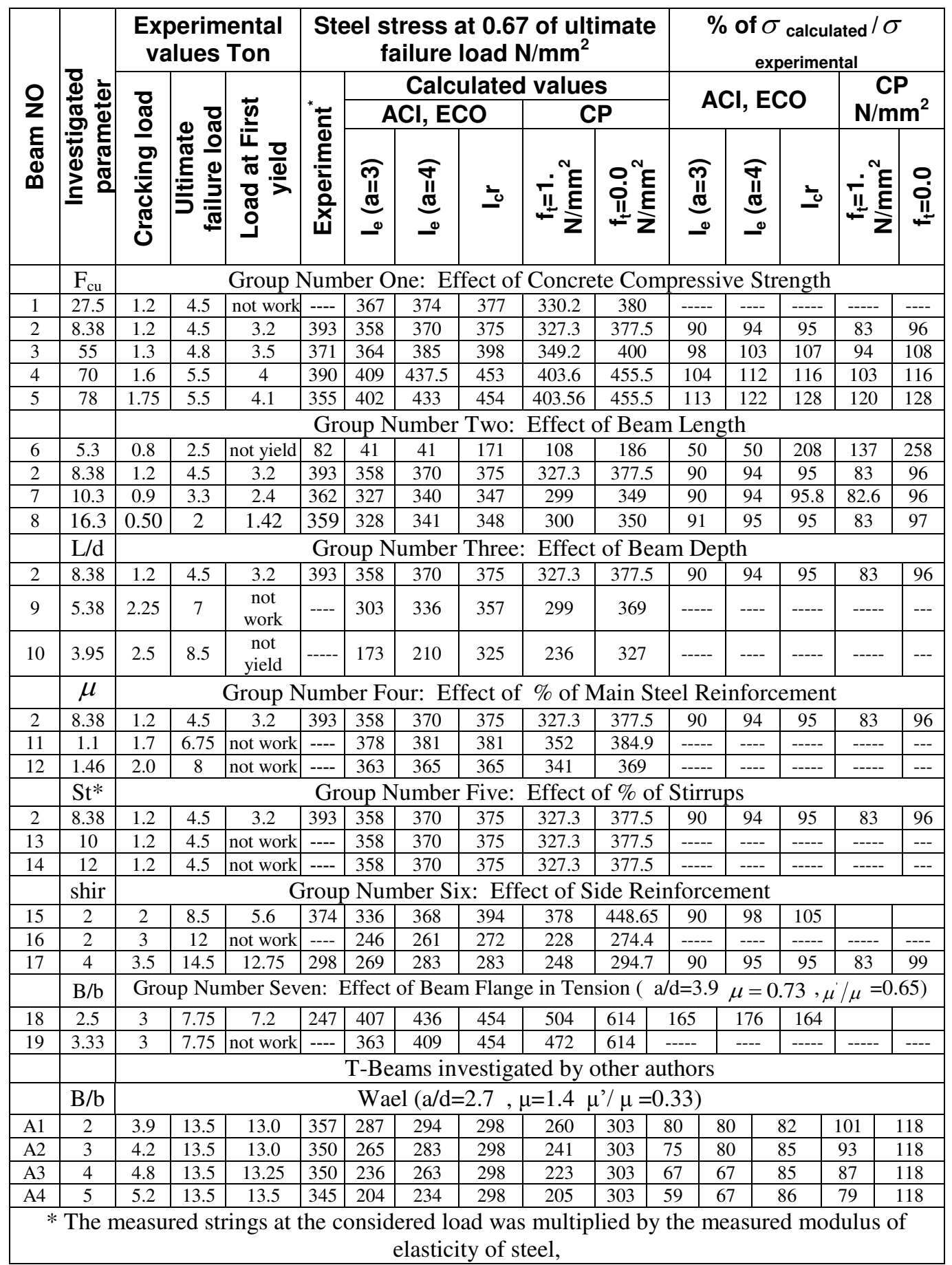




\section{7- 4 Comparison Between the Experimental Results and the Analytical Results of Beams Tested Experimentally By Other Authors}

One Rectangular beam tested experimentally by Ahmed [22] and four T beams tested experimentally by Wael [23] are investigated analytically. The properties of these beams can be found in [22, 23]. A summary of predicted behavior of these tested beams using codes of practices deflection equation is given in tables (6 and 7).

(a) Rectangular Beam Tested Experimentally By Ahmed (22) $\left(\mu=0.88, \mu^{\prime} / \mu=\right.$ $0.0, \mathrm{~L} / \mathrm{d}=6.7, \mathrm{a} / \mathrm{d}=2.8$, no Shrinkage steel used, no compression steel used with C320): The approximate procedure serious underestimates the computed deflection compared with corresponding experimental value (it underestimates by 53\%). This may be due to the effect of shrinkage for concrete owing to the absence of the compression steel.

(b)T Beams Tested By Wael(23) $\left(\mathrm{a} / \mathrm{d}=2.7 \mu=1.4, \mu^{\prime} / \mu=0.33, \mathrm{~L} / \mathrm{d}=6.7, \mathrm{a} / \mathrm{d}=2.8\right.$, on Shrinkage steel uses, four different values of $\mathrm{B} / \mathrm{b}(2,3,4,5)$ are considered). The codes of practice's equations for deflections overestimate the computed deflections compared with the experimental values. The percentage of overestimation depends on the estimated values of moment of inertia. For the considered case of study ACI and CP110 $[9,11]$ overestimate the deflection by average values of $(35 \%$ to $25 \%)$ and $(33 \%$ to146) respectively depends on the flange to web breadth.

\section{8- CONCLUSIONS}

1. The available codes of practices equations [5 -7] underestimate the true maximum values of deflection of Rectangular Reinforced Concrete Beams. The percentage of underestimation increases as the ratios of both compression steel to tension steel and shear span to depth decrease.

2. The available codes of practices equations [5 -7] overestimate the true maximum values of deflection of $\mathrm{T}$ Reinforced Concrete Beams. The percentage overestimation increases as the ratio of the flange width to the web width increases.

3. To improve the efficiency of the approximate procedure of computing deflection using equations of codes of practices [ $5-7$ two terms are needed to be included in this equation:

(a) The deflection due to the effect of shear deformation.

(b) The deflection due the shrinkage of unsymmetrical reinforcement in beams.

More elaborate analysis is needed to accurately take such effects into account.

4. The comparison between the experimental and the analytical values of deflection shows that, there is no much difference in the computed deflections with using $\mathrm{I}_{\mathrm{e}}$ $(a=3$, or $a=4)$ or $I_{c r}$, which means that it may be there is another source of deflection (such as shear deformation or shrinkage of concrete) or the value of modulus of elasticity of concrete which is used in the elastic theory is uncertain, which means that value of modulus of elasticity which is taken in the codes of practices as instantaneous modulus of elasticity needs to be justified according to the load level.

5. The major difficulty in the application of elastic theory to reinforced concrete members are the inelasticity of concrete, the displacements of a reinforced concrete member, even under working loads, strictly requires a non-linear analysis. In this 
analysis deflections due to shear and shrinkage deformations should be included [13 - 17]. Nowadays, such analyses are easy to be done in design office.

6. Although the approximate procedure of codes of practice underestimates the deflection of rectangular section and overestimates the deflection of $\mathrm{T}$ sections, it gives a reasonable prediction of stresses in steel at the service limit load.

\section{9- REFERENCES}

[1] Arafa Abdo Mostafa Abou-lafaa" Study of Moment Redistribution in Concrete Beams", Faculty of Engineering- Alexandria University, 1993.

[2] Nethercot-Da; Li-TQ; Ahmed-B "Plasticity of Composite Beams at Serviceability Limit State", Structural Engineering, V 76 n 15 Aug 1988, P289-293.

[3] Stewart-Mark-G, " Serviceability Analysis of Reinforced Concrete Structures,", Journal of structural engineering, V 122 n7 Jul 1996, P794-803..

[4] Griffis-Lawrence-G " Serviceability Limit States Under Wind Load ", Engineering -journal, V 30 n 1 st quarter 1993, P1-16.

[5] Egyptian Code of Practice for design and Construction of Reinforced Concrete Structures, No.203, 2001.

[6] ACI Committee 318, "Building Code Requirements for Reinforced Concrete (ACI 318-95)" American Concrete Institute, Detroit, 1995.

[7] Committee Euro-International du Beton, CEB-FIP, Model Code 1991.

[8] CP 110 part 11972 "The Structural Use of Concrete" B. S. I London,1972".

[9] Branson D.E "Deformation of Concrete Structures" McGraw-Hill, New York 1977.

[10] Park R. and Pauley T., "reinforced Concrete Structures" New York. Wlley, 1975.

[11] P Bhatt " Problems in Structural Analysis by Matrix Methods", Longman Inc, New York, first published 1981.

[12] AL. Manaseer, A.A., "A Nonlinear Finite Element Study of Reinforced Concrete Beams" ,Ph. D. Thesis, University of Glasgow, Glasgow, U.K August, 1983.

[13] L. M. Abdel -Hafez, "Direct Design of Reinforced Concrete Skew Slab". Thesis Glasgow University, Glasgow, UK (1986).

[14] Mudathir Solieman Mohamed "Finite Element and Experimental Study of Reinforced concrete in torsion", Glasgow University, Glasgow, UK (1986).

[15] K. Youssef, M. Ghoneim, A. Gendy, and M. Issa, "Non-Linear Finite Element Analysis of Reinforcement Concrete under Short Term Monotonic Loading, Part 1 : Constitutive Model", The eight Arab structural engineering conference Cairo university, Faculty of Engineering Structural Engineering Dept., 21-23 October 2000 PP 641-657

[16] K. Youssef, M. Ghoneim, A. Gendy, and M. Issa, "Non-Linear Finite Element Analysis of Reinforcement Concrete under Short Term Monotonic Loading, Part 2 :Evaluation of The Constitutive Model", The eight Arab structural engineering conference Cairo university, Faculty of Engineering Structural Engineering Dept., 21-23 October 2000 PP 659-665

[17] CP 110, "Hand Book on the Unified Code for Structural Concrete", Cement and concrete association, 52 Grosvenor Gardens, London SWIW QAQ, 1972. 
[18] Hashim, M.M, "Shear Response of Reinforced Concrete T-Beams to Static and Repeated Load", M.Sc., Thesis, Assiut University, Egypt, 1979.

[19] Tawfik., Y.R. "Characteristics of R.C. Beams Reinforced and Coated Stirrups under shear Failure", M. Sc. Thesis, Minia University, Egypt, 1997.

[20] Yuliang, X.S.T., Hino S. and Chung W., "Shear Ducitlity of Reinforced Concrete Beams of Normal and High-Strength Concrete", ACI structural Journal Vol. 19, No. 2, March-April 1994.

[21] Zinab Ebratheem., Yehia A. Hassanean, A.Megahied," Effect of Side Bars on the Shear Strength Properties in Large Concreter Beams", The eight Arab structural engineering conference Cairo university, Faculty of Engineering Structural Engineering Dept., 21-23 October 2000 PP 455-467

[22] Ahmed Fathalla Mohamed El-min, "Structural Behavior of Bi-Cold Deformed Steel Concrete Compresite Beams", Civil Eng. Dept., Faculty of Eng., Assuit University, Assuit, Egypt

[23] Wael Abd-Ellah Kaoud, "Flexral Behaviour of Reinforced Concrete TBeams with the Flange on the Tension Side", Civil Eng. Dept., Faculty of Eng., El Minia University Minia, Egypt 2005

جدارة معادلة الأنحناء الخاصة بالمواصفات القياسية في حساب الأنحناء القصير المدي

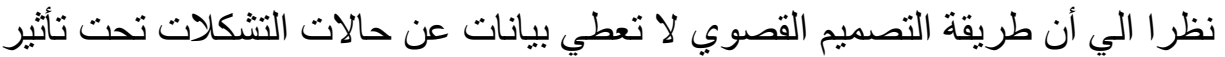

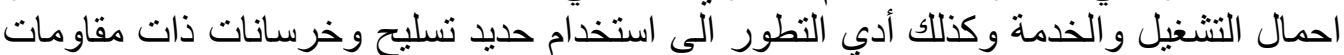

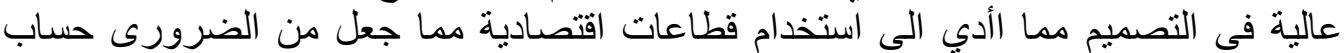

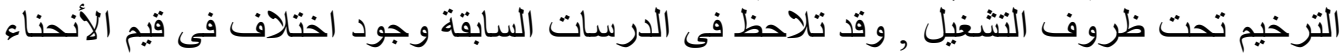

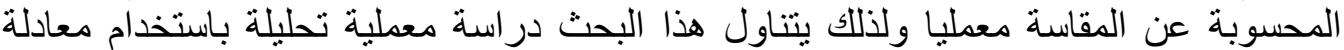

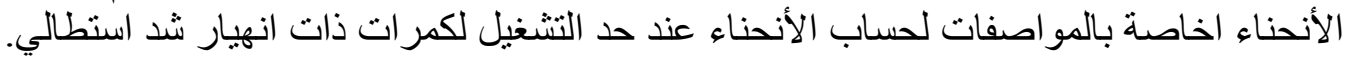

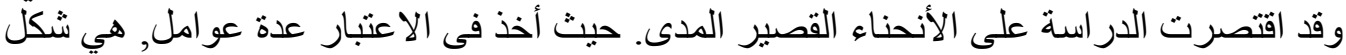

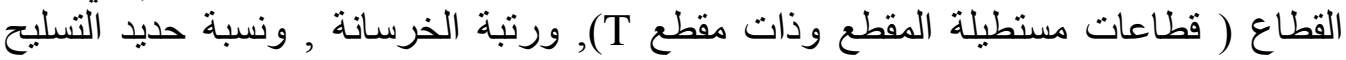

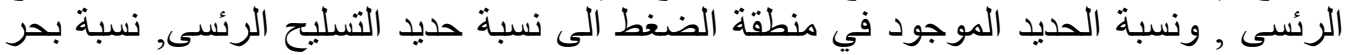
القص الى العمق الفعال ووجود حديد جانبي،ونسبة الحديد الجيدة الجزعي (الكانات) أوضحت الرئست الدراسة

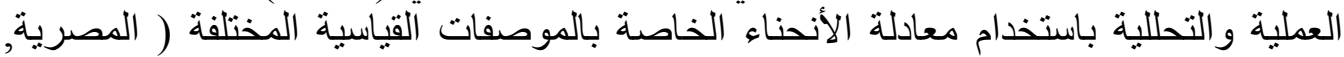

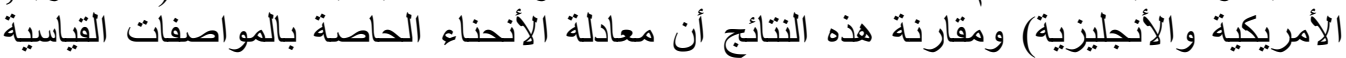

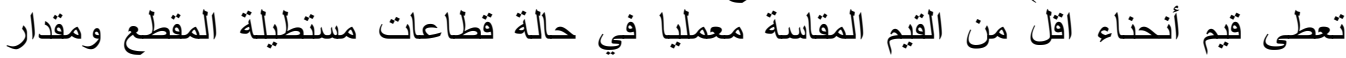

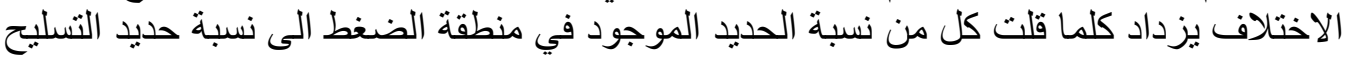

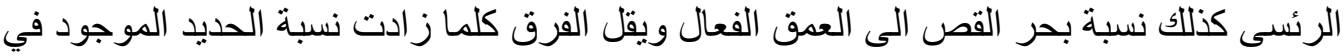

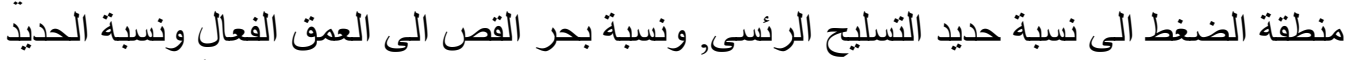

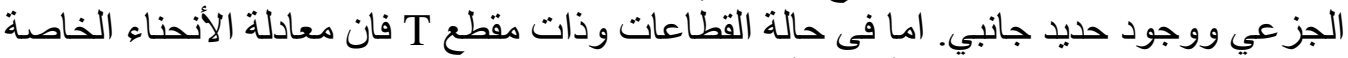

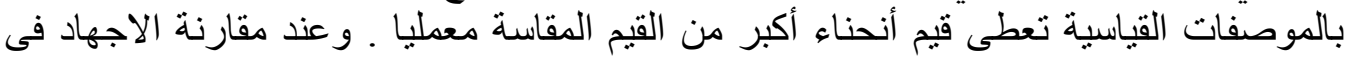

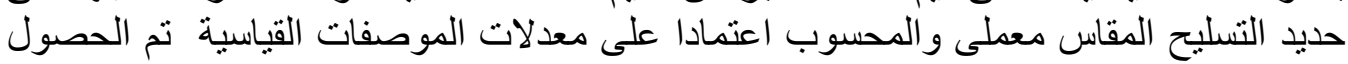
على نتائج مرضية لجميع الحالات. 